\title{
PORTS, TRÀFICS, VAIXELLS, PRODUCTES: ITALIANS I CATALANS A LA MEDITERRÀNIA BAIXMEDIEVAL
}

\author{
CORAL CuADP.ADA \\ Universitat Rovira $i$ Kirgili (Tarragona) \\ ANGEla ORLANDI \\ Universitd di Firenze (Itälia)
}

\section{SUMARI}

Introducció- 1. Les fouts.- 2. Els moviments portuaris: el port valencià (1394-1396).- Els moviments portuaris: Barcelona, Mallorea i València (ss. XIII-XV). - 4. La tipologia dels vaixells. - 5. Algunes reflexions $\mathrm{i}$ vies d'anàlisi de futur.

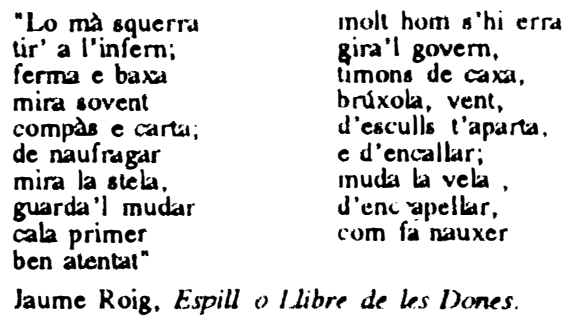

Jaume Roig. Espill o llibre de les Dones.

\section{INTR@DUCCIÓ}

Aquest present treball dual és en certa manera una continuació d'anteriors estudis parcials que fan referencia al tema que ens ocupa', pero

\footnotetext{
${ }^{1}$ Vegeu Comal Cuadrada, Puertos comerciales en la Edad Media, "Cuademos de Historia 16", Madrid, 1989, n' 166; Canne BATIJ1, Joan BUsqUITA, Coral CUADRADA, Notes sobre l'eix comercial Barcelona-Mallorca-Barbaria, segona meitat s.XIII, "XIII Congrés d'Història de la Corona d'Aragó, Comunicacions I", Palına de Mallorea, 1989, pp.33-47; Coral CuADRADA, Relaciones comerciales entre la Corona de Aragón e ltalia en el paso del Medioevo a la Modemidad, Rapporti Genova-Mediterraneo-Allantico nell'Età Modema, Gènova, 1990, pp.483-500; Canne BATl.1.1, Coral CUADRADA, Berenguer de Bonastre, un negocianse barcelonés en el Norte de Africa (segunda milad del siglo XIII), "Miscellania di Studi in Memoria di Alberto Boscolo", Roma, 1991, pp.125-146; Coral CUADRADA, M' Dulores LOPEZ, La

"Anuario de tistudios Medievales", $24(1994)$
} 
que alhora significa una ampliació notable d'horitzons interpretatius i d'objectius de recerca ${ }^{2}$. Una ampliació que inclou dins dels seus propis paràmetres un treball en equip que sigui capaç d'englobar perspectives diverses dins d'una mateixa realitat, elements aquests que havien estat ja assenyalats com a molt necessaris per d'altres historiadors, entre els quals cal citar Federigo Melis ${ }^{3}$. En dir aixo ens referim sobretot als a: pectes relatius a un millor coneixement de l'economia catalana del segle XIV en sentit concret; de manera més genèrica, al seu rol dins del marc de les interrelacions amb els centres portuaris italians coetanis, immergits tots en un àmbit més ampli que consideraria un món mediterrani de bescanvis, pero també un altre d'atlàntic.

Pel que fa als elements metodologics, cal insistir en els pressupdsits previs del nostre estudi. Representa, ben cert, una tasca conjunta, pero no redactada a quatre mans, sinó complementària, és a dir: s'enfoca des de dos punts de vista i a través de dues investigadores que s'han basat majoritàriament en fonts arxivístiques diverses, encara que alguns dels objectius de la recerca -els que han fet possible escriure aquestes IInies- hagin estat coincidents ${ }^{4}$. D'aquesta manera, trobem que una única situació historica pot ser considerada, amb dependència de les fonts, de manera sincronica $i$

Medilerrinia Medieval: les socielats inercantils a la Corona d'Aragó (s.XIV), "Universitas Tarraconensis", X (1992), pp.67-92; Coral CUADRADA, Del calalà del Tres-cents $i$ d'altres dicalectes, "Revista de Catalunya", 62 (1992), pp.62-79. Angela ORLANDI basa les seves reflexions en la seva tesi de llicenciatura, encara inèdita, que té per títol Aspetri e caratteristiche del mercato valenzano alla fine del Trecento. Un' indagine sul carleggio datiniano Valenza-Palinas di Maiorca, con trascrizione dei documenti, Florència, 1991.

${ }^{2}$ Que Coral Cuadrada ha pogat portar a teme mercès a dues corcessions d'ajuts per part de la DGICYT' (Direcció General d'Investigació Científica i Tècnic 1): la primera, dins del Programa de perfeccionament i inobilitat del personal investigador, amb referència BE91-351; la segona, dins del d'Utilizació de Recursos Científics, amb referència URC-16/92. Ambdues són compleınentàries al projecte de recerca finançat igualment per la DGICYT amb referència PS91.0072, del qual Coral Cuadrada n'és investigadora principal.

${ }^{3}$ Federigo MEIJS, L'area catalano-aragonese nel sistema economico del Mediterraneo accideniale, "IX Congresso della Corona d'Aragona", Nàpols, 1978, I, pp.191-209. La conveniència de conjugar la documentació italiana amb la catalana o castellana s'ha repetit amb insistència, ressaltant sempre que calia contrastar les informacions fomides pel buidatge dels nostres protocols notarials i els provinents d'arxius italians de caràcter comercial; $c f$, per exemple, Alberto BOSCOLO, Catalani nel Medisevo, Bolònia, 1986, pp.9-21; i les indicacions d'Antoni FURIo, recordant la iinportància de l'Arxiu Datini de Prato per a conèixer amb major profunditat realitats pròpies, cf. València, un inercat medieval, València, 1985, pp. 21-22.

"Coral Cuadrada ha sumat la seva recerca als arxius catalans amb les efectuades a l'Arxiu Datini de Prato. Angela Orlandi ha trehallat al dit arxiu i, pels efectes que siguin pertinents, s'ha de eonsiderar a Angela Orlandi l'autora de la meitat del text, senyalada convenientment amb asterics. La traduccio de l'article d'Orlandi ha estat realitzada per Coral Cuadrada. 
diacrònica, és a dir, pensant en l'evolució i/o en el temps concret. A més, és aquest un intent de confrontació de dades, d'apreciacions i de constatació de fets.

En conseqüencia, el nostre article s'estructura en dues parts ben diferenciades -i ressaltades gràticament per mitjà dels asteriscs triples-, a partir d'aquestes ĺnies introductories. La primera d'aquestes ha estat realitzada per Angela Orlandi, que examina els punts enunciats al tit(ol del nostre estudi, a partir de la correspondencia de l'arxiu Datini de Prato corresponent als anys 1395-1398 i girada entre les subseus de Valencia i Mallorca. La segona per Coral Cuadrada, que planteja els moviments portuaris des d'un cicle de llarga durada, des de l'inici del segle XIII tins a les primeres dècades del quatre-cents, emprant dades documentals provinents de diversos arxius $^{5}$.

Una darrera advertencia, ahans de passar a l'exposició de les nostres recerques, té a veure amb la terminologia. Si repassem el títol ens adonem de la paraula "catalans", per la qual hem optat per a referir-nos als mercaders barcelonins, valencians i mallorquins, com a d'altres ciutats del principat, del Rossello o la Cerdanya de l'època tractada, no de forma arbitrària, sino per raons documentals bastant obvies. En primer lloc, són anomenats amb aquest terme els comerciants dels principals ports dels Països Catalans operants a l'estranger a l'epoca'; en segon lloc, així també es consideraven els productes, com els panni catalaneschi citats als registres de duanes i manuals de mercaderia, sense distincio d'origen; i, en tercer lloc, quan Francesco di Marco Datini decidi obrir les seves filials a la Corona d'Aragó, a la darreria del segle XIV, el nom de la societat fou el

\footnotetext{
SSón els següents, amb les ahreviatures entre parinatesi, que utilitaucun a continuaciós. Arxiu de la Corona d'Aragó (ACA), Arxiu de la Catedral de Barcelona (ACB), Arxiu Higtìric de Protocols de Barcelona (AHPB), Arxiu del regne de Mallorea (ARM), Arxiu del regne de València (ARV), Archivio di Stato di Pisa (ASPi), Archivio di Stalo di Prato Archivio Datini-(ASP, AD), i els Arxius Departamentals dels Pirineus Oriental: (ADPO).

"Vegeu, per exemple, les transcripeions de Tito ANTONI, I "partituri" mutiorchini del "Inu dels Pisans" relativi al commercio dei Pisani nelle Baleari (1304-1.122 e 1353.135.5), Pisa. 1977; $i$ en especial Rosa Calluna CeCcheTtT, Giovama LusChI. Siella Maris Zunino. Genova e Spagna nel XIV secolo. II "Drictus Calc!lanoruin" (I 386, 1392.93), Ginova, 1970.

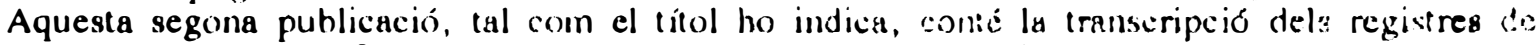
duana genovesos, referents als anys inencionats, on qualscvol inereader procedent d:is ports dels Paisos Catalans era considerat, i registrat, per tant, com a català
} 
de Compagnia divisa di Catalogna, amb nuclis Barcelona, Mallorca i Valencia.

Amb aquest breu article volem exposar els primers resultats d'una recerca sobre el paper que el port i la plaça de Valencia exercien a la $\mathrm{Me}$ diterrània a la darreria del segle XIV, el moment en el qual les relacions entre l'Oceà Atlàntic i el Mare Nostrum dels romans creixien tant en intensitat com en freqüencia.

En aquest es recullen algunes consideracions sobre l'estudi i, en especial, sobre les modalitats d'ús d'una font del tot particular com la de la correspondencia comercial.

A fi de definir els extrems relatius al camp historic investigat, cal presentar la documentació emprada, reprenent, encara que de forma sintetica, una reflexió que no és nova ${ }^{7}$ sobre aquest particular tipus de font, justificant-ne la tria i precisant-ne la intensitat i les possibilitats informatives, els límits i les mancances.

El primer aclariment que s'imposa és el de la consideració de la correspondencia comercial i la dels documents comptables.

Mentre als llibres de comptabilitat hom es limitava a registrar, purament i simple, els factors numerics i quantitatius de l'operació economica, a les cartes comercials, en canvi, els esdeveniments són detalladament descrits $i$ analitzats de forma qualitativa. La correspondencia permet coneixer circumstàncies i aspectes de tipus econòmic, polf́tic i social de l'epoca, mostrant aixl, per a cada indret, una capacitat i una potencialitat informativa que no podem menysvalorar.

La correspondencia és, doncs, la prova de la complexitat dels tràfics mercantils, de les característiques de les empreses i del desenvolupament de la mentalitat dels operadors economics; aixo comporta una gran riquesa de dades i d'informacions que poden ser propiament utilitzades per als objectius de l'anàlisi sòcio-economica.

Si d'una banda la fiabilitat dels continguts és una conseqüencia directa pel fet que aquest material es extremadament ric i la multiplicitat de missives, d'emissors, de destinataris, de temps i de llocs possibilita una multiforme i complexa visió dels fets, sovint comparables entre ells mercès

\footnotetext{
${ }^{7}$ La problemàtica inherent a la utilització de les fonts procedents de les empreses comercials dels segles XIII-XVI ha estat àmpllianent tractada per F. MELS, Documenti per la Storia Economica, Florèncit, 1972
} 
a les diferents versions que en donen els mateixos que ens els descriuen per tant, són susceptibles d'emprar-los per a una anàlisi d'historia economica-, de l'altra, ens trobem també davant del límit concret del principi fonamental que inspira la correspondencia $i$, per tant, el seu contingut.

Aquest, en efecte, havia de garantir al mercader el ràpid i oportú coneixement de les característiques i de les condicions dels mercats, a fi de poder elaborar igualment les previsions oportunes i les decisions operatives.

Per aquesta rao, a les cartes, a més de les informacions relatives a les mercaderies, als canvis de moneda, a les activitats dels operadors economics, a les rutes seguides, als mitjans de transport emprats, a les notícies de tipus metrologic i fiscal, s'hi troben detalls sobre els costums i sobre les normes que regulaven els mercats estrangers.

Altrament, la correspondencia era, a l'època, l'únic instrument amb el qual els operadors economics podien bescanviar informacions, parers $i$ coneixements: un altre motiu que fa tan rics i multiformes els continguts de les cartes.

Sovint l'arribada d'una carta a destinació depenia del bon resultat d'un negoci o del major o menor interès en una certa inversió. Per aixo a la correspondencia d'aquell temps es troben amb freqüencia recomanacions d'operadors que demanen que se'ls envii "..., in servigio, 2 versi per ogni barcha..." $\mathrm{i}$ que el no escriure "... è grande verghongna a tutti, perché preghovi non sia più e più per li amici che per noi"9.

Per tant, si la recerca als fons de la correspondencia s'efectua de forma crítica, sense oblidar que els resultats que sorgeixen dels estudis efectuats en aquests tipus de documents han de ser sempre i sobretot referits al mercader que ha redactat la missiva i a la realitat geogrâfica a la

\footnotetext{
${ }^{8}$ Archivio di Stato di Prato, Archivio Datini (a continuació ASP, AD), no 1077, carta 07.II.1397.

${ }^{9} \mathrm{ASP}, \mathrm{AD}, \mathrm{n}^{\circ}$ 1077, carta 21(28). II.1397. Les citacions són recomanacions de Luca del Sera a Cristofano di Bartolo Carocci da Barherino. Luca era el director de la societat valenciana de la "Compagnia Divisa di Catalogna" del mercader pratenc Francesco di Marco Datini, de la qual era també soci. L'establiment datinià a Catalunya es componia dels nuclis de Barcelona, València i Mallorea. Luca arribà a València el 9 o 10 de juliol de 1396, tot seguit dotà la filial d'una seu correcta i d'aixó n'infornà ràpidament: "I' o tolto casa così bella come sia in questa terra e atta a ogni cosa colla migliore mostra ci sia a' drapi di lana e cosi di seta... Costa lb. 33 l'anno..." (ASP, AD, $n^{\circ}$ 1077, carta 22.VII.1396). Cristofano di bartolo Carocci da Barberino era, en canvi, director de la seu de Palma de Mallorea, substituí Ambrogio di Lorenzo de' Rocchi, que el 12 de juny de 1396 era "...andato a Paradiso..." (ASP, AD, no 1077, carta 07. VII.1396), com ho escrivia un dels factors de la companyia.
} 
qual pertanyia o de la qual feia referència, és possible obtenir d'aquesta font les informacions més àmplies i diverses, tant des del punt de vista geogràfic com des dels nombrosos matisos amb els quals els factors de l'economia del temps vénen analitzats. Respectar aquest principi de recerca justifica, d'una banda, la utilització d'aquest tipus de documentació, i ens autoritza, de l'altra, a intentar descobrir i caracteritzar els fenomens economics centrats, en el nostre cas particular, al mercat de Valencia.

I també perque, malgrat tot, només la correspondencia comercial, encara que elaborada per homes gravats per la responsabilitat de la direccio d'una empresa $i$, per tant, interessats en tot allo que directament o indirectament podia influenciar el resultat de llur activitat, fa possible el coneixement d'informacions no tan sols economiques sino, alhora, de caràcter historic i social, mantenint la vivacitat i la riquesa de la narració de qui viu, encara que no sigui sempre en primera persona, l'esdeveniment en el seu progressiu advenir ${ }^{10}$.

És per tant ben cert el valor de les fonts directes mercantils, que permeten la reconstrucció i la interpretació de forma acurada del sentit i els termes de l'estructura economica d'aquell temps, encara que la preocupació per estudiar l'ambient tan sols en funció de l'activitat desenvolupada era el filtre a través del qual seguia el discurs del mercader, testimoni involuntari d'aquells fets.

La documentació original $\mathrm{i}$ inèdita de la qual la nostra recerca pren les seves bases és la correspondencia datiniana de Valencia a Palma de Mallorca ${ }^{11}$.

\footnotetext{
${ }^{10}$ Per captar la vivacitat de la narració que pot oferir una carta comercial és suficient llegir el judici que el soci del Datini, a València, donà de la ciutat: "La città mi piace forte: ed è ben trionfievole e di molto più stima ch'i' non are' imaginato..." (ASP, AD, n ${ }^{\circ} 924$, València-Barcelona, carta 07.V.1407).

"Les cartes objecte d'aquest treball són les corresponents al registre no 1077 conservat a l'Arxiu Datini de Prato. L'estudi aprofundit de totes aquestes, considerant tots i cadascun dels elements informatius que ofereixen, constituí la nostra tesi de llicenciatura, dirigida pel professor Giampiero NIGRO i defensada a la Facultat d'Economia i Comenc de la Universitat de Florença l'any 1990, amb el títol: Aspetti e caratteristiche del inercato valenzano alla fine del trecento. 'Un' indagine sul carteggio datiniano Valenza-Palma di Maiorca, con trascrizione dei documenti. Totes les missives surten de la plaça de València $i$ tenen una única destinació: Mallorca. Els emissors presents són 33; els que compten amb un nombre major de cartes expedides són els de la Companyia Datini de la ciutat. Les dades extremes dins de les quals es troba la correspondencia examinada són el 27.07.1395 i el 22.03.1398. Es tracta dels anys que varen veure el naixement de la Compagnia Divisa di Catalogna $i$, en particular, la pròpia i veritable constitució de la delegació valenciana, i l'assumpció d'aquesta com a casa mare als Països Catalans. La recerca es va concentrar en les 260 cartes (entre elles tres foren escrites
} 
L'estudi d'aquesta documentació, encara que limitada en el temps i en l'espai, fa possible el recull de noticies i permet elaborar i organitzar les primeres sensacions que en provenen. Les dades i les consideracions que ara presentem seran oportunament integrades amb l'anàlisi d'ulteriors fons de la correspondencia i dels llibres comptables, el contingut dels quals enriquiran les notícies fins aqur conegudes, per la historiografia italiana i catalana, sobre el rol que el port i el mercat valencià exerciren a la fi del tres-cents.

En particular, serà important aprofundir en l'àmplia documentacio girada entre les tres seus (Valencia, Barcelona i Mallorca) de la companyia catalana, completant-la amb aquella relativa a l'empresa datiniana de Florència. Investigació que permetrà reconstruir de manera més precisa els diferents esdeveniments, mitjançant, com ja ha estat subratllat, les diferents descripcions dels fets fornides pels emisors particulars.

Els temes presents en aquest grup de cartes són, com s'ha dit, diversos $\mathrm{i}$ heterogenis, però més ordenades apareixen les notícies de les sortides i entrades de les embarcacions al port i de les seves característiques qualitatives; aquestes ajuden a reconstruir les comunicacions maritimes i les línies de navegació seguides; per tant, també les mercaderies i els itineraris comercials més importants, al llarg dels quals s'alimentaven els principals corrents d'intercanvi i llur freqüencia.

Dins de l'àmbit d'aquest esquema inicial i de presentació de dades s'insereixen tots els altres elements que vénen a completar el quadre, no tan sols de les relacions marítimes del port de la ciutat, sinó també de les característiques del mercat valencià. La vivacitat d'aquest mercat depenia, almenys en part, de la freqüencia dels viatges de les embarcacions carregades de mercaderies.

Juntament als vaixells a l'entrada i a la sortida del Grau, animaven el port mercaders, mariners, armadors, barquers ${ }^{12}$, oficials encarregats de les imposicions fiscals sobre els productes carregats o descarregats de les

en català) que componen el registre: un nombre limitat de missives, però concentrat en un període de temps relativament modest que consen poder oferir unes primeres impressions.

${ }^{12}$ En especial armadors i barquers havien de ser també bastant nombrosos, comptant amb la particular naturalesa geografica del port que, fins al 1494, no tenia moll, of J. GUIRALHADZIIOSSIF, Valence, Port Méditerranéen au XV siècle (1410-1525), Paris, 1986, p. 47. 
embarcacions, i finalment, no pas per manca d'importancia, les mercaderies que hi arribaven o aquelles que en sortien.

En realitat, la imatge del tràfic del Grau de València que sorgeix de l'examen de les dades presents a la correspondencia mostra els límits amb els quals cal comptar.

La primera limitacio ve representada pel fet que, en general, totes les informacions relatives a la circulacio marítima procedents de la documentacio tenen com a únic denominador les necessitats dels directors datinians en relacio al coneixement dels mitjans navals utilitzables per a llurs expedicions, i el moviment de les embarcacions que s'esperaven de forma particular car, per exemple, transportaven carregues desitjades des de força temps, o perque eren de considerable valor.

De fet, ells volien estar sempre informats sobre els moviments dels vaixells, encara que sovint aquestes notícies es referien només a les naus més grans $o$ a aquelles que transportaven càrregues particularment interessants per al mercat valencià. Aixl, els corresponsals, en llurs missives, requerien contínuament informes sobre les embarcacions en aquell moment disponibles $\mathrm{i}$ aptes per a satisfer llurs exigencies, sia d'expedicio o de recepcio de mercaderies ${ }^{13}$.

En aquestes mateixes informacions també hi estaven ben interessades les empreses germanes de la Companyia de Catalunya i llurs col.laboradores.

Per aixo, allo que a primera vista pot semblar només un límit esdevé un avantatge, perque els mercaders seguien, en llurs cartes, els desplaçaments de les naus pas per pas, car d'aquests depenia l'arribada a destinacio de les partides de mercaderies que hi havien carregat.

Es creava d'aquesta manera una intensa i puntual xarxa d'informacions, constituilda per la participacio activa no solament dels directors de les filials datinianes sino també per les missives dels operadors economics de les altres empreses en relació amb les delegacions catalanes.

\footnotetext{
${ }^{13}$ Un exemple significatiu d'aquesta intensa xarxa de comunicacions creada entre els mencaders ve d'una carta del 10 de maig del 1396, que deia: "Qui [Valencia] non v'è al presente niuna nave che fosse buona da noleggiare per Pisa... Noi ci siamo poi meglio informati del fatto della nave dite aresti bisongno per Pisa e dicieci uno amicho che qui nella chostiera e una buona nave di Bischaia di 180 tonelli, la quale andrebe a Pisa e a Genova. Altra nave e' verebe costì e cosi per questa chostiera infino a Barzalona, ma domanda fiorini 1000 di Firenze, che sarebe chara: vorebe aversi per fiorini 700 in 800 , e pero avisate di vostra intenzione..." (ASP, AD, no 1077, carta 10.V.1396).
} 
Entre l'octubre i el desembre del 1395 descobrim, entre molts exemples que podríem citar, una rica correspondencia entre Tuccio di Gennaio, del grup Tecchini, Guido Caccini a Valencia i Ambrogio di Lorenzo, en aquells moments director de la filial de Mallorca. Ens informen de les arribades $\mathrm{i}$ dels moviments de les diverses embarcacions en llurs connexions entre el Mediterrani i l'Atlàntic, de les mercaderies que s'hi carregaven i del recíproc ajut en la reserva dels carregaments.

La nau de Niccolaio Madrias i la guiada per Piero Arinbau ${ }^{14}$, provinents de Flandes, arribaren a Valencia a la fi d'octubre. Llur articulat viatge preveia aturar-se als ports de Barcelona i Mallorca i després tornar a Valencia, d'on sortiria una altra vegada cap a Flandes.

El nolit de part del carregament de les dues naus es comissionà a la companyia valenciana dels Caccini per Ambrogio di Lorenzo, el qual, havent de carregar a Palma de Mallorca roba di peso no havia tingut dificultat a obtenir-lo.

El nolit di fermo requerit a Mallorca es componia de 50 mesures de comi, 3 d'anis, 6 de safrà i 8 de grana, amb un pes conjunt de 300 quintars. La part di rispetto era en canvi requerida per 30 mesures d'arros, corresponents quasi a 120 quintars.

D'una carta de Guido Caccini sabem després que Ambrogio va aconseguir noliejar a la nau de Madrias només 50 quintars entre coml, safrà i grana; per aixo, quan l'embarcació arribà a Valencia, el corresponsal s'espavila per fermarle una altra porció de carregament suficient per a poder embarcar almenys 200 quintars de mercaderies.

La nau d'Arinbau, als inicis de desembre era encara a l'illa i el factor confirmà al director mallorqui un nolit de 25 costals de comi, 4 bales de grana i 3 o 4 bales de safra's.

Pero quan l'embarcació fou a València, no essent encara disponibles les mercaderies que li destinaven, els Caccini varen haver de veure-la partir amb amargor vers Flandes, sense haver-hi pogut carregar res. Cal subratllar que tal preocupacio. era reforçada pel coneixement que, en parti-

\footnotetext{
${ }^{14}$ Els noms i cognoms s'indiquen en la seva exacta versió documental.

${ }^{15}$ Els nòlits indicats pel carregament d'aquestes dues embarcacions foren els següents: "... Costumasi dare di nolo del comino, grossi 18 in 20; del zafiore, 25 in 30; della grana grossi 36 in 40; mandorle, grossi 14 in 16, franchi di tutte avarie..." (ASP, AD, no 1077, carta 31.X (03.XI). 1395).
} 
cular en els anys que examinem, hi havia un excés de sol.licituds de nolits amb referència a la disponibilitat d'embarcacions. Una més atenta verificacio, que haurà d'estendre's als anys successius, podria assumir un significat important pel que fa a la valoració de les tendencies economiques conjuntes de l'àrea baleàrico-valenciana ${ }^{16}$.

També la famflia veneciana dels Corner es dirigi a Luca del Sera i a Cristofano di Bartolo a fi que s'ocupessin del nolit de la Mariona, embarcació nova de 700 bótes que els Corner enviaren a les mars de Catalunya, per primera vegada el gener de 1398.

Amb les paraules del director valencià l'operació es descriví segons el detall següent:

Il fermare costa roba e qui siamo avisati. De' Comeri abiamo qt. 500 pasati, questi non so se gli darò, perché ancora non o libertà; one di nostri amici da qt. 550 e de' Banchi,sì che oltre a' Comeri, qt. 800 in 900.

Attendolo ongnora, per essere chiaro quello leverd a noi ${ }^{17}$.

S'han volgut evidenciar aquests exemples concrets per assenyalar com els interessos comuns $i$ les relacions directes entre els operadors fan que, ara si, la documentació assoleixi una major amplitud, alhora que esdevé més especffica. I, malgrat no permetre reconstruir de manera completa el moviment del port $i$, per tant, la dimensió numerica i la nacionalitat del vaixell que atracava al Grau, possibilita aprofundir l'anàlisi sobre les causes i els modes amb els quals es desenvolupà l'activitat marítimo-comercial relativa a aquesta zona, influenciant els tràfics de les mercaderies, tant des d'un punt de vista qualitatiu com quantitatiu.

Tan sols l'estudi dels mitjans de transport i dels viatges consentia a aquells homes individualitzar ràpidament els trets i l'organització maritima que de forma més oportuna podien ser emprats per a la satisfaccio de les exigencies de llurs activitats.

\footnotetext{
${ }^{16}$ És significatiu el que escriu, amb referència a aquest tema, Guido Caccini: "Noi avemo da' vostri di Barzalona di noleggiare alla nave viniziana insino a 1500 quintali e chosì era nostra intenzione di fare, ove avessimo potuto, ma insino a qui non s'eे potuto fare che di 200 quintali. Voi dite ora lo scrivano è chostì e che dicie none pud levare più che insino in 1000 quintali, sicché posedone noleggiare, oltre a que' sono noleggiati, 800 quintali, il faremo e quello seghuiremo il saprete..." (ASP, AD, no 1077, carta 15(21).III.1398).
}

${ }^{17} \mathrm{ASP}, \mathrm{AD}, \mathrm{n}^{\circ}$ 1077, carta 15(21).III.1398. 
La segona limitació, en canvi, es deu al restringit àmbit espacial i temporal, poc menys de tres anys, al qual els documents es refereixen. Es podrien obtenir resultats més vàlids si s'utilitzessin, almenys per al mateix perfode de temps, paral.lelament, les cartes girades des d'altres places amb les quals la filial valenciana estava en relació directa.

Si volem fotografiar millor les característiques del port valencià $i$ reconstruir totes les notícies referents de manera especifica-a les embarcacions que freqüentaven el port, en particular llur consistencia numérica, llur nacionalitat i la de llurs patrons, llur capacitat i llurs equipaments, seria necessaria una documentació molt més àmplia que l'emprada fins al present nivell de la recerca.

D'altres han estudiat de forma aprofundida aquest tema, pero usant fonts que, en els millors dels casos, son relatives als primers anys del quatre-cents ${ }^{18}$.

El que diversifica aquesta breu anàlisi és només la utilització d'una font escrita tan especial que és capaç d'imprimir un tall, del tot particular, a la recerca. És, certament, la documentació d'una empresa i per tant d'un mercader, pero precisament per aixठ permet individualitzar tot el substrat de les estructures mercantils, de les decisions contractuals i dels esdeveniments que es trobaven a la base de l'ordenació dels tràfics $i$, en conseqüencia, també per l'organització de l'activitat marítima.

Constantment, de la lectura dels documents, es percep que el port de Valencia es col.locava a l'interior dels grans circuits del comerç marítim de l'epoca.

Luca del Sera, a les seves cartes adreçades a Cristofano, des del juny del 1395 al mars de 1398, dóna notícia de 213 naus que arriben i surten del port. La majoria de les embarcacions provenia de Mallorca o hi anava.

Aixi, més del $55 \%$ dels vaixells que, en el període al qual es refereix la correspondencia, partiren del Grau de Valencia, es dirigien a l'illa; quasi el $8 \%$ inflava veles en direccio a Bruges o Flandes; el mateix percentatge d'embarcacions es movia cap a Genova; el $7 \%$ anava directament a Pisa i el $3 \%$ a Venecia i a Gaeta. La part restant venia representada per les

\footnotetext{
${ }^{18}$ La documentació valenciana emprada per J. Guiral-Hadziiossif, que constitueix la base de la seva obra ja citada es refereix tota a èpoques successives.
} 
embarcacions que unien la ciutat amb els ports de Barbaria o amb els altres ports de les costes catalanes i castellanes ${ }^{19}$.

La mateixa cosa succeïa amb les naus que atracaven al Grau valencià. En aquest cas, una vegada més, de Mallorca provenien més del $40 \%$ dels vaixells que arribaven a port; quasi l' $11 \%$ tenien com a procedencia els ports de Barbaria; el $8 \%$ venia de Bruges. La part restant comprenia ${ }^{20}$ diferents provinences, entre les quals Venecia, d'on arribaven més del 5\% dels vaixells; o Pisa, Genova i Barcelona, amb percentatges poc superiors a l'1\%.

Tot el que acabem de dir és encara més evident als gràfics A i B, del final de l'article.

De la lectura d'aquests valors cal, pero, tenir present les hipdtesis i les suposicions sobre les quals es fonamenta el calcul. En relació al primera gràfic, és necessari subratllar com les destinacions indicades s'han d'entendre com a destinacions finals de les embarcacions; en resulten, per tant, excloses totes les eventuals etapes intermedies sovint previstes al mateix contracte de nolit ${ }^{21}$.

Pel que fa a l'alt percentatge de vaixells que partien a Mallorca, es pot afirmar que una bona part d'aquests tenien alguna destinació final al port concret de l'illa ${ }^{22}$, però és també cert que les embarcacions més grans, aptes per a navegacions més llargues, prosseguien llur viatge vers d'altres ports.

Consideracions anàlogues valen també per a l'anàlisi de les dades referents a les embarcacions que atracaven al Grau de Valencia ${ }^{23}$. Seria un

\footnotetext{
ció.

${ }^{19}$ Per al $6,4 \%$ de les embarcacions no ha estat possible individuar les localitats de destina-

${ }^{20}$ En aquest cas, el percentatge de les embarcacions per a les quals la correspondència examinada no permet reconstruir el port de procedència és del $25 \%$.

- ${ }^{21} \mathrm{De}$ la documentació, per exemple, es comprova que in Teriglio, havent noliejat la seva nau per Gènova, pel contracte fou obligat a amarrar a València "... 15 di utoli e 4 a Paniscola e 3 a Barzalona..." (ASP, AD, no 1077, carta 25.Xl.(01.XII).1396), seguint així el típic itinerari que preveia allo que $\mathbf{F}$. Melis anomena "el tomb de la costa".

${ }^{22}$ Aquesta consideració ve avalada també per l'observació de les embarcacions utilitzades per a aquests desplaçaments que eren, sovint, barques $i$ llaüts que sabem que s'utilizzaven en general per al petit cabotatge.

${ }^{23} \mathrm{El}$ fet que de la font es desprengui que la majoria de les embarcacions entrant $\mathrm{i}$ sortint del port valencià vinguessin o anessin a Mallorca es justifica, en part, per la naturalesa mateixa de la correspondència. Una correspondència que, com ho hem senyalat, es mantenia entre la seu de Valéncia $i$ la de Palma $i$, per tant, reflectia un interès marcat pels directors d'ambdues delegacions, en relació a ambdós ports.
} 
error pensar que aquestes dades són completes. En efecte, de la mateixa documentació s'escolen notícies i referents, relatius sobretot al moviment de petit cabotatge que, de ben segur, havia de ser més aviat més ampli i superior als altres.

Molts elements fan pensar que del port de Valencia s'estenia una intensa xarxa de comunicacions navals, no solament vers Mallorca sino també vers la regió costera mediterrània, especialment la compresa entre Barcelona i Màlaga.

Pero, sobretot, al sud de Valencia es trobaven tota una serie de ports i de localitats de dimensions més o menys rellevants, de les quals llur relatiu apropament o allunyament de la ciutat eren de gran importancia per al mercat de tota la regio valenciana.

Encara que, si d'aquests moviments marítims no hi ha més que rares traces a la correspondencia, no obstant aixo és cert que entre Valencia i els ports d'aquest litoral es desenvolupava un intens trafic de petites embarcacions. Efectivament, les terres interiors de Valencia i Malaga eren ben importants per a la producció de la fruita, dels safrans, de la grana i dels cuirs. I per aixd, certament, no podien mancar els adequats enllaços maritims entre el Grau i els ports de Denia, Xàvea i Xàtiva, centres on aquests productes es recollien per ser, després, redistribuïts.

L'escassetat de referencies al cabotatge procedent d'aquests ports troba en part una justificació en el fet que la seu datiniana de Valencia enviava, a aquelles localitats, els seus operadors, els quals pensaven ells mateixos a carregar ametlles, datils, figues i panses a les embarcacions directes a Flandes. Era tanta la importancia i l'interes que tenia la fruita seca per als operadors de Bruges, que fou disposada fins i tot "una nau de la fruita", destinada de manera exclusiva al transport d'aquestes mercaderies $^{24}$.

També els ports col.locats al llarg del litoral comprès entre València i Barcelona devien estar ben enllaçats amb el valencià. Eren, en

\footnotetext{
${ }^{24}$ F. MELSS, Malaga nel sistema econornico del XIV e XV secolo a L. Frangioni (a cure di), 1 mercanti italiani nell'Europa medievale e rinascimentale, Florencia, 1990, p. 117. D'aquesta embarcació es retroba una menció directa a la documentació. El director valencia ens informa d'un col.laborador seu, Lodovico di Francesco Stefani, el desembre de 1397, que havia tomat feia poc "... da spacare la nave della frutta..." (ASP, AD, no 1077, carta 14(18).XII.1397).
} 
efecte, localitats de concentracio i redistribució de la llana, dels safrans i de la mel que procedien de la regio del Maestrat.

L'observació de la tipologia de les embarcacions que movien el port ens ajuda, dins de certs límits, a la reconstrucció de les vies comercials que convergien i al mateix temps irradiaven del Grau de Valencia; perque cada vaixell presentava tals caracteristiques de cabuda, dimensions, agilitats i velocitats diverses; com per a fer-los aptes per a alguns tipus de desplaçament i no pas per a uns altres.

Les galeres $\mathrm{i}$ les naus, vaixells de dimensions importants, eren aptes per la navegació d'altura.

A la correspondencia, són freqüents les referències als moviments de les galeres venecianes, les quals rarament feien etapa a Valencia i preferien Mallorca, Eivissa o Alacant. Les embarcacions venecianes podien atracar als ports 'dels Països Catalans només després d'haver obtingut la llicència necessària ${ }^{25}$, la concessió de la qual depenia de com, aleshores, es resolia el perenne conflicte d'interessos entre les exigencies de l'erari de la Corona ${ }^{26} \mathrm{i}$ els patrons locals que, junt amb d'altres potencies estrangeres, veien reduïdes, per als venecians, llurs oportunitats d'acció.

Per a les galeres, sobretot, quasi mai hi havia la seguretat d'utilització de port, ja fos a l'anada o al retorn de Flandes. Fins a les acaballes del 1399 , les naus venecianes pogueren servir-se de Mallorca, pero llur presència fuig del port, quasi de sobte, el $1400^{27}$. A partir d'aquests anys, les.

\footnotetext{
${ }^{25}$ En aquest sentit, sembla significatiu el contingut d'una missiva que la Companyia dels Orlandini de Bruges adreça el 1404 a la filial datiniana de Barcelona. L'escriptor s'expresava així: "Le ghale' viniziane in questi 15 di sieno preste, ma non àno licenze di porre in chotesto Regno che alla Chantera e perché là pare si paghi s. 1 per libbra non c'è chi vogla dare per la roba e pochi mada da Vinegia: atendono risposta o forse aranno licenza dalla Singnoria di porre a lviza che a pocha speranza ne stanno" (ASP, AD, n 855, Bruges-Barcelona, carta 23. VIII. 1404).

${ }^{26}$ Durant el segle XIV les entrades pecuniàries, ordinàries $\mathrm{i}$ extraordinàries, no foren suficients per afrontar les despeses de la monarquia. Per tant, els sobirans foren obligats a alienar gran part dels béns que constituien el patrimoni reial; per això, Martí l'Humà es veié obligat a endegar una política econòmico-fiscal força enèrgica i capaç de reomplir els fons de l'estat, cf. M.T. FERRER I MALLL, El patrimoni reial $i$ la recuperació dels senyorius jurisdiccionals en els estats catalano-aragonesos a la $f i$ del segle XIV, "Anuario de Estudios Medievales", 7 (1970-1971), pp.448-449.

${ }^{27} \mathrm{G}$. NIGRO, Le vicende economiche incentrate su Maiorca rivissute attraverso il carteggio datiniano, nel 1392-1400 (con trascrizione delle lettere), tesi de llicenciatura inżdita, dirigida per Federigo Melis a la Facultat d'Economia i Comerş de la Universitat de Florència, 19701971, p.274.
} 
embarcacions venecianes es veuran obligades a concentrar-se a Eivissa ${ }^{28} \mathrm{i}$ fer a continuacio, de tota manera, estada al port d'Alacant ${ }^{29}$.

D'aquest darrer depenia la provisió dels mercats locals de productes originaris, no tan sols de Venècia sinó també d'aquells del nord d'Europa, i dels altres ports als quals feien escala. Ells garantien així el forniment d'aquestes mercaderies, que eren descarregades als centres castellans $i$ catalans, on s'omplien els vaixells amb tots els productes que de la peninsula ibèrica s'exportaven als mercats italians i mediterranis.

La nau era una embarcació de propulsió a vela, empráda per a la navegació d'altura ${ }^{30}$, molt gran i amb força capacitat, apta per al transport de considerables quantitats de mercaderies, ja que es podia aprofitar fins $i$ tot l'espai que als altres vaixells era ocupat pels remers. Les dimensions de les naus, tot $i$ essent elevades, variaven d'embarcació a embarcació, i sovint s'expressaven en bótes.

Per exemple, dels documents s'evidencia que les naus castellanes, amb un tonatge en general oscil.lant entre 200-400 bótes eren més petites que les d'altres nacionalitats. Aixı, a les missives llurs referències vénen donades amb expresions diminutives, com navetta o ...nave chastellana pichola... ${ }^{31}$, malgrat constatar que es consideraven de ...buon passagio $0^{32}$.

\footnotetext{
${ }^{28}$ F. MEus, Malaga, cit, p. 142.

${ }^{29} \mathrm{~A}$ continuació vénen reflectits els ports on les galeres venecianes feren etapa d'anada i de retom de Flandes, sempre en relació als anys considerats a la correspondéncia: $-1395,26$ de setembre, de retorn, Mallorca; -1396, abril, d'anada, Mallorca; -1396 setembre-octubre, de retom, Alacant i Mallorca; -1397, d'anada, Mallorca; -1397, setembre, de retorn, Alacant i Mallorca; -1398, marc, d'anada, Mallorea. Aquesta contínua incertesa sobre el port que podia ser emprat per a la pausa de les embarcacions sorgeix també de la documentació. En una carta de Luca del Sera, així s'escrivia: "Non si sa cierto se lle viniziane discharicheranno a La Cantera: sai questi veniziani fanno quello viene loro a punto. Diroti che sentino" (ASP, $A D$, no 1077, carta 10. VII.1397).

${ }^{30} \mathrm{~F}$. SEVILLANO COLOM, Navegaciones inediterráneas (siglos XI-XVI). Valor del Puerto de Mallorca, a R. Ragosta (a cura di), Navigazioni mediterranee e connessioni continentali (secoli XI-XVI), Napols, 1982, p. 60.

${ }^{31}$ Respectivament: ASP, AD, no 1077, carta 21(28).II.1397 i ASP, AD, no 1077, carta 07.VII.1396. Aquesta consideració es confirma despres per un dels corresponsals, que subratllava que per a l'expedició de la llana no podien ser utilizzades les naus castellanes, perque aquesta mercaderia era massa voluminosa: "... Se qui fose venuta, arebbe auto robe assai, çod lane, ma per questa nave chastellane non s'à mestiere: troppo velume ell'à..." (ASP, AD, $n^{\circ}$ 1077, carta 21(28).II.1397).
}

${ }^{32} \mathrm{ASP}, \mathrm{AD}, \mathrm{n}^{0}$ 1077, carta 21(28).II.1397. 
del Mediterrani mitjà (de Sardenya, Sićlia, Campània i Àfrica septentrional) i les d'Ultramar ${ }^{33}$.

Les fortunes economiques de Valencia anaren molt vinculades al fet que des d'aquesta ciutat i del seu port partien les més importants vies de comunicacio vers els altres territoris de Castella i de la Corona d'Arago, els de major interès comercial ${ }^{34}$.

Aquestes regions s'identificaven, al nord, amb el triangle els vèrtexs del qual eren representats per Morella ${ }^{35}$, Sant Mateu i Tortosa; al sud, la costa mediterrània fins a Alacant i Màlaga;i a l'est,les illes balears, especialment Mallorca.

La primera regio era molt vital per a la producció de mel, cera, safrans i sobretot de llana ${ }^{36}$.

La proximitat relativa de Valencia a aquesta zona constituïa per a la ciutat una gran rellevància economica; aixi, gradualment, el mercat valencià (com succer tambe amb la companyia Datini) hi assolf un pes no pas indiferent, sobretot pel que fa al comerç de la llana ${ }^{37}$.

Dels documents es desprèn que gran part de les operacions alle lane es portaven a terme als centres de Morella i de Sant Mateu, on Luca del Sera ${ }^{38}$ marxà diverses vegades ... solo per avere lane... ${ }^{39}$.

${ }^{33} L$ 'expansió del comerç portà veritablement els catalans fins a Rodes, Alexandria, Beirut, Candia $i$ Xipre. Vegeu en aquest sentit C. CARRERE, Barcelone, centre économique à l'époque des difficultés 1380-1462, Paris, 1967; i M. DEL. TREPPO, I inercanti catalani e l'espansione della Corona d'Aragona nel secolo XV, Nàpols, 1967.

${ }^{34} \mathrm{~F}$. MEus, Aspetti della vita economica medievale (studi nell' Archivio Datini di Prato), Siena, vol. I, p. 259.

${ }^{35}$ M.M. BolX, Contacto mercantil de Morella con Francesco di Marco Datini, . Primer Congreso de Historia del País Valenciano", II, València, 1980.

${ }^{36}$ Tanta era la importància d'aquesta zona per a l'activitat dels .speradors econòmics de l'època que: "Les empreses de grans dimensions tenien filials en aquestes regions espanyoles: sobretot a Sant Mateu, però també a Morella, i més enllà, a Terol i fins i tot a l'interior, fins a Montalbà", citat a F. MELS, La llana de l'Espanya mediterrània i de la Barbaria occidental en els segles XIV-XV, a A. Furió (ed), València, un inercat medieval, València, 1985, p.68. En aquest sentit, vegi's també G. NIGRO, Els opercadors econdınics italians als palsos catalans entre els segles XVV i XV. El cas de Tuccio di Gennaio, València, cit, pp. 50-52.

${ }^{37}$ F. MEus, Mercaderes italianos en Esparia (siglos XIV-XVI), Sevilla, 1976, pp. 146-147.

- ${ }^{30}$ Aquests desplaçaments del director valencià de la ciutat es justificaven per la importància que les compres de llana gaudien en l'economia de la filial. D'altra banda, la compra-venda d'aquesta mercaderia estava molt influenciada per la relació de confiança entre els operadors, i en particular estava reglamentada per costums concrets $i$ inderogables. Al desembre del 1397, Luca marxa a la Plana, on esperava aconseguir: "...inanzi ongni altro, le buone lane vi sono, questo per una aınistà d'uno de' magiori che v'è..." (ASP, AD, no 1077, carta 15(20).XI.1397), i al març del 1398 encara explica com "...non è maniera di fare pregio delle lane, 
Movent-nos vers el sud es trobava una àrea compresa entre Valencia i el cap de Sant Antoni, del cap de Sant Antoni a Alacant: era aquesta la línia ideal que unia Alacant i Valencia. Aqui era on es produïen per excel.lencia els safrans i sobretot la fruita seca, dos dels productes clau del mercat valencià.

Més al sud, Múrcia i Oriola, centres de producció de la grana; i el regne de Granada, aquella part de la península que a l'epoca estava encara sota dominació àrab. Pel que fa a les relacions comercials amb aquesta regio, Valencia exercia un paper molt rellevant. Era certament la intermediària privilegiada per a l'exportació dels productes musulmans, en particular la seda d'Almeria, el sucre de Malaga i els cuirs de l'interior de Granada.

A la plaça valenciana es trobaven també pells birbaresques, la procedencia de les quals era referida a tot el nord d'Àfrica, i cuirs della terra, és a dir, de les regions internes del regne de Valencia i de Castella. En particular, a la documentacio surt una produccio exclusivament valenciana de cuir, definit ...della Cha vicina di qui.. ${ }^{40}$, amb un preu a l'abril de 1396 de 15 a 18 lliures, probablement el quintar, encara que, a la correspondencia, l'única vegada que es menciona no s'hi indica la unitat de mesura.

Per delinear de manera més precisa les relacions mercantils que el mercat valencià tenia amb el de Palma, cal d'antuvi assenyalar el particular rol economic que l'illa desenvolupava. Mallorca portava a terme activitats de concentració $\mathrm{i}$ distribució d'un gran nombre de béns produïts o consumits en un conjunt territorial molt ampli.

D'una banda, es reunien a Mallorca els productes provinents de Barbaria i els agrícoles procedents de la península iberica, inclosa Valencia, els quals, juntament amb les llanes balears, s'expedien més tard a Itălia i als altres països de la Mediterrània. D'altra banda, arribaven a l'illa considerables quantitats de mercaderies, com especies, perles, laca, paper i argent de Venecia, draps florentins, acer i substàncies tintories de Pisa, teles

perché non ronperebono l'usanza che mai fanno pregio se non a Pasqua di cinquagesima..." (ASP, AD, no 1077, carta 12(16).II.1398).

${ }^{36} \mathrm{ASP}, \mathrm{AD}, \mathrm{n}$ 0 1077, carta 29.X.1397.

${ }^{40} A S P, A D, n^{\circ} 1077$, carta 24.IV.1396. 
i fil d'or de Gènova; d'allà es redistribuïen en direcció als ports catalans i castellans, a Flandes i a Anglaterra ${ }^{41}$.

És sobretot aquesta funcio de concentració i de distribució de mercaderies la que determinava i caracteritzava les relacions comercials entre Valencia i Mallorca. Com s'evidencia pels documents, sense oblidar naturalment les cauteles que una analisi limitada comporta, els mercaders valencians feien arribar a llurs corresponsals mallorquins les sol.licituds de productes que es recollien al port de l'illa, portats per galeres venecianes o per les galeotes d'Alcúdia.

Aixo significa que els operadors de València cercaven d'elaborar per a cada producte previsions de venda, intentant alhora establir-ne la utilitat que en podrem aconseguir. Després, decidien l'oportunitat de fer-se enviar les mercaderies per veure si podien vendre-les al mercat de la ciutat 0 , en cas contrari, de renunciar-hi, i deixar que els factors de Mallorca pensessin de vendre-les in situ o en qualsevol altre lloc.

La regió més septentrional del comerç valencià comprenia Anglaterra i Flandes, en particular la important plaça comercial de Bruges ${ }^{42}$. La documentació mostra com Mallorca i València, més que Barcelona, eren els ports majoritàriament emprats vers les rutes marítimes de Flandes ${ }^{43}$.

Les places nordiques es revelaven de gran importancia, no tan sols per al mercat valencià, sino també per la totalitat de les places catalanes. Cap a Flandes es dirigia una gran part de la producció agrícola local: safrà, grana, fruita seca, arros, mel, oli; $i$ una bona part de les mercaderies que arribaven dels països d'Ultramar, com les especies, l'alum, la gualda, el cofoll $i$ el $\cot ^{64}$. D'Anglaterra, de França septentrional, de Flandes $i$ del Brabant arribaven, en canvi, draps de llana.

${ }^{4} G$. NIGRO, Le vicende, cit, pp. 241-242.

${ }^{42} \mathrm{C}$. CARRERE, Barcelone, cit, p. 570.

${ }^{43}$ En aquest sentit, Simone Bellandi, des de Barcelona, escrivia: "Ogni volta avete a mandare per di qua roba in Fiandra, sia più tosto a Maiolica e Valenza che qui: ché più spesso à paxagi per là, che qui. E sopratuto zolfo, che à di spesa qui più che altrove: solo di lelda di qui, d.7 per lb.; e gienerale d'entrata e uscita d.5..." (ASP, AD, no 434, Barcelona-Pisa, carta 09.III.1396).

${ }^{4}$ La font indica amb precisió quins eren els productes que de manera particular anaven destinats a aquests mercats. En una carta llegim: "...qui è ora pocha roba per Fiandra: tra 'Liso ed io abiamo qualche quintale 300 , tra chomino e datteri e riso e asfrore e grana..." (ASP, AD, no 1077, carta 18(21).III.1398). 
Les embarcacions que venien de Flandes, una vegada superat l'estret de Gibraltar, seguien un itinerari precís per lliurar els draps de Wervicq i Courtrai ${ }^{45}$, a fi de reduir al mínim el pagament dels impostos que els gravaven. Aquest recorregut es ben delineat al text següent, extret de la documentació:

\begin{abstract}
Crediamo che que' di Brugia arete avisati sopra a' panni, a cio che ve n'abiano potuto mandare per li ghalee, 4 o 6 balle e crediamo lo farano. E i panni per questa tera [Valéncia] crediamo lascierano alla Chantera e quelli per costi [Mallorca] e per Barzalona lascierano costì che none verd̀ bene a punto al vitachalle, ma sarà di più profitto de' merchatantiti ${ }^{46}$.
\end{abstract}

\title{
1. LES FONTS
}

La documentació que hom pot emprar, conservada als arxius catalans, valencians $\mathrm{i}$ mallorquins, a fi d'avaluar els moviments del comerç $\mathrm{i}$ dels intercanvis a la baixa medievalitat, és ben múltiple i rica. Una primera divisio prové de les fonts de tipus oficial i de les de tipus privat. En relació a la primera, cal citar en primer lloc els fons de l'Arxiu de la Corona d'Aragó. En aquest cas, com ho ha senyalat Rafael Conde ${ }^{47}$, podem trobar, primer, fonts documentals relatives als impostos ordinaris i extraordinaris, susceptibles d'anàlisi estadística del moviment del port de Barcelona i de les percepcions dels drets d'importació i d'exportació de productes,

\footnotetext{
${ }^{45}$ Sovint s'explicita la composició de les bales de draps de Wervicq: " 1 balla di 8 panni di Vervi, cioc 2 morati, 4 feretti, 1 cilestrino, 1 vermiglio, alle 13 d'azurro..." (ASP, AD, $n^{\circ}$ 1077, carta 19. VI.1397).

${ }^{46} \mathrm{ASP}, \mathrm{AD}, \mathrm{n}^{0}$ 1077, carta 04(07).V.1397. Nombrosos eren els procediments utilizats pels mercaders per reduir al mínim el pagament de taxes; en una altra ocasió, Luca del Sera, per comprar draps de la terra destinats a Gènova, proposava la següent "astúcia": "...perché di doane paghino meno, farosi scrivere al cartolaro carichò in Barzalona." (ASP, AD, no 1077 , carta 25.XI.(01.XII).1396). A més, per a algunes peces de draps de Damasc, enviats de Mallorca a Valencia, aconsellava a Cristofano de fer-ne "..2 fardelli e per 2 barche segretamente cieli mandate e non si pagui nulla che d'è poca cosa e cosi fate. Avisate i padroni che qui a noi li diono per lo simile modo." (ASP, AD, n 1077, carta 06.V.1396).

${ }^{47} \mathrm{La}$ documentación para el estudio del comercio bajomedieval catalán: problemas y perspectivas, "Anuario de Estudios Medievales", 10 (1980), pp. 653-658.
} 
imposats als mercaders estrangers ${ }^{48}$; segon, els d'algunes lleudes ${ }^{49}$. El tercer grup de fonts fa referencia a les autoritzacions o concessions de privilegi per comerciar amb productes prohibits ${ }^{50}$. Caldria afegir-hi que un estudi sistematic $i$ aprofundit hauria de considerar aquestes fonts confrontant-les amb les dades provinents dels Registres de Cancelleria $\mathrm{i}$ amb les dels llibres comptables $i$ notarials conservats al mateix arxiu 0 en uns altres. És ben cert que seria necessari un esforç considerable per portar endevant una accio de tals característiques ${ }^{31}$ que, malgrat tot, ens aproparia de forma més adient a un millor i sempre més desitjable coneixement del tema.

L'Arxiu del Regne de Mallorca conté documentació en alguns aspectes bastant analoga a l'esmentat de la Corona d'Arago. Son de rellevancia les sèries de Guiatges i Ancoratges, els de Lletres Comunes, a més dels de Coses Vedades ${ }^{32}$ i els de lleudes $^{33}$. Pel que fa a l'Arxiu del

\footnotetext{
${ }^{40}$ Per a posar uns exemples, ACA, Mestre Racional, B. Dret d'ancoratge; A. Comerç amb Orient; A. Comerç prohibit; A. Lleuda; A. Drets reials sobre el comerç exercit per alemanys i savoians; Generalitat de Catalunya, Generalitats. Aduases.

"Lea lleudes de Valencia, Alcira, Burriana-Sagunto-Xativa-Biar, Saragossa, Alago-Gallur, Sadaba, Canfranc, Candasxú, Ebre, Perpinya, Puigcenda, vall de Querol, Colliure, Tortosa, Barcelona, Tamanit, Cambrila i Tortose foren publicades $\mathrm{i}$ analizzades per M. GUAL CAMARENA, Vocabulario del Comercio Medieval. Colección de aranceles aduaneros de la Corona de Aragón (siglos XIII y XIV), Tarragona, Diputación Provincial, 1968.

${ }^{50}$ Són les relatives als registres de les intitulades "coses vedades", of Pilar FRAGO, M" Dolores LOPEZ, Barcelona $i$ el comers mediterrani $i$ atlantic a partir de les llicencies de navegació (1400-1410), "XIII Congrés d'Història de la Corona d'Aragó. Comunicacions III", Palma de Mallorca, Institut d'Estudis Baledrics, 1990, pp.171-184. Tambe aón força interescants les critiques a la incorrecta utilizació d'aquestes fonts a $M^{*}$ Dolores LOPEZ, La Corona de Aragón y el Norte de Africa: las diferentes direas de inservención mercantil catalano-aragonesa en el Magreb a finales del siglo XIV y principios del siglo XV. "Acta Historica at Archroologica Mediacvalia", 11-12 (1990-1991), pp.303-305 i notes 16-22. Uns andiai en profunditat de la incidzncia del comerg prohibit a J. TRENCHS, "De Alexandrinis" (El comercio prohibido con los musulmanes y el papado de Avinón duranse la primera misad del siglo XV), "Anuario de Estudios Medievales", 10 (1980), pp. 238-318.

${ }^{31}$ Vegeu, per exemple, les consideracions fetes en avaluar el coneixement actual que tenim del regnat de Pere el Cerimoniós, a Carme BATUE, Joan J. BUSQUETA i Coral CUADRADA, - Balance de las actividades historiográficas en Catalunta durante los últimos diez antos, a Presente y Futuro de la Historia Medieval en Espana, Madrid, Univervidad Complutense, 1990, p. 144; i tambe les indicacions suggerides a Coral CUADRADA, El desconegut segle XIV, "Revista de Catalunya", 56.(1991), p. 62.

${ }^{2}$ Vegeu una primera aproximació a F. SEVILLANO COLOM, Mallorca y Valencia: relaciones marrimo-mercantiles en el siglo XIV, "Primer Congreso de Historia del País Valenciano", II, Valencia, Universitat de Valencia, 1980, pp. 539-551.
} 
Regne de València, cal considerar, amb especificacions molt similars als anteriors arxius esmentats, les sèries de Cancelleria, Guiatges i Governacio (Suplicacions). Els problemes que plantegen aquestes fonts són, especialment, llur fragmentació ja que, malauradament, no en disposem de sèries contínues. A més, seria necessari alhora avaluar llur relativa credibilitat, perque és prou conegut que les informacions precedents de documentacio fiscal estan sempre subjectes a un no menyspreable marge d'error ${ }^{54}$. Evidentment, les dades provinents d'áquests fons de caràcter oficial tenen llur importància, cosa que és obvia; tanmateix, s'han de contrastar amb les de naturalesa privada.

A partir del buidatge dels protocols notarials i dels llibres de comptabilitat d'empreses mercantils, la informacio s'incrementa i es diversifica notablement. No volem dir pero que, amb la conjuncio d'unes i altres dades, s'arribi a un $100 \%$ de la realitat documental del moment; ara bé, les primeres apreciacions que s'obtenen de l'estudi dels registres oficials es modifiquen de forma substancial en l'avaluar l'actuació dels particulars. A les tres ciutats portuàries hi ha protocols nombrosos pel que fa a l'arc cronologic dels XIII-XV, tant als Arxius dels Regnes mallorquf $\mathrm{i}$ valencia, com també als Arxiu municipals, de protocols i de la catedral de Barcelona. Cal dir que cap d'aquests ha estat encara buidat completament, atesa la inherent dificultat i la gran dosi de laboriositat que representa una tasca d'aquesta mena. No obstant aixo, per a alguns perfodes i per a alguns notaris concrets, la informació podem considerar-la exhumada en la major parts.

${ }^{53}$ Les lleudes mallorquines han estat estudiades per A. RJERA MELS, La Corona de Aragón y el Reino de Mallorca en el priiner cuarto del siglo XIV. I. Las Repercusiones Arancelarias de la Autonomia Balear (1298-1311), Madrid-Barcelona, CSIC, 1986.

${ }^{34}$ Com a exemples, cal repassar les declaracions de mercaders catalans que sol.liciten guiatges per a comerciar amb Sicília $i$ després vénen acusats de traficar al nord d'Àfrica, of TRENCHS, "De Alexandrinis", cit; o la utilització d'intennediaris per a portar a terme un conjunt de negocis, of CONDE, La docuinentación, op. cit; o els intents de frau ressaltats per Angela Orlandi a la primera part d'aquest treball, vid. supra, nota 40.

"ss A Barcelona, és necessari citar la ingent labor realitzada per Madurell, Garcia Sanz i Ferrer Mallol, veure per exemple: J.M. MADURELL MARIMON-A. GARCIA SANZ, Comandas comerciales barcelonesas de la baja edad inedia, Barcelona, Colegio Notarial de BarcelonaDepartamento de Estudios Medievales (CSIC), 1973; A. GARCIA SANZ- M.T. FERRRER MALLOL, Assegurances $i$ canvis maritims inedievals a Barcelona, Barcelona, Institut d'Estudis Catalans, 1983, 2 vols.; A. GARCIA SANZ-J.M. MADURELL MARIMON, Societats mercantils medievals a Barcelona, Barcelona, Fundació Noguera, 1986, 2 vols.; M.T. FERRER MALLOL, 
De tota manera i si, fins i tot, assolíssim fitxar, document a document, tots $\mathrm{i}$ cadascun dels folis dels manuals dels notaris conservats als grans arxius i encara els dels petits centres costaners -Blanes, Sant Feliu, Tarragona, Tortosa, entre d'altres-, ens trobariem amb dificultats metodologiques que cal explicitar. D'una banda, mai podrlenn dir que gaudim de la totalitat de la informacio, perque sempre hi havia negocis que es feien de forma no contractual, o que empraven segons i tercers per a portar-los a terme $\mathrm{e}^{\mathrm{s}}$.

Pel que fa a l'actuació dels mercaders estrangers a casa nostra, l'accio dels comerciants toscans pren especifitats ben particulars. És ben clar que la presencia forastera és antiga a les terres de la Corona d'Ara$\mathrm{g}^{67}$; ; en especial hi constatem, com he feu Guy Romestan, la intensitat d'operacions d'occitants operants a Valencia a la primera part del trescents. Pero ja és una qüestió menys obvia la possibilitat d'intitular aquest

Els italians a terres catalanes (segles XII-XV), "Anuario de Estudios Medievales", 10 (1980), Pp. 393-466. A Valencia, una aportació ens parla de la recerca en fons notarials, E. CRUSEUES, Jerarquización y especialización de los circuitos mercantiles valencianos (finales del XIV-primera initad del XV), "Anales de la Universidad de Alicante", 8 (1990-91), pp. 83-105. Per Mallorca, un aspecte parcial del comerç ha estat posat en relleu per M.D. LOPEZ, La Corona de Aragón y el Norte de Afica, op. cit. Una valoració conjunta de les àrees comercials dels Països Catalans a la baixa edat mitjana a C. CUADRADA, M.D. LOPEZ, La Mediterrania Medieval, op.cit. Evidentment, no hem volgut donar un llistat exhaustiu de tots els articles $\mathrm{i}$ estudis elaborats sobre el teına del comerç, ni al principat ni als regnes; optem tan sols per a citar-ne alguns d'interessants.

s6És el cas de les procures, coinandes marítimes $\mathrm{i}$ comandes mercantils, com la que fa Jaume de Forés, mercader de Barcelona, a la societat de Bonfuhu i Isaac Bonavia, jueus barcelonins, de 30 lliures de inoneda barcelonesa de tem per a comerciar a Narbona $i$ a tota la Provença (1316-06-26, AHPB, Pere de Torre, M.1316, f.102). Un exemple de procura el trobem el 12 de juliol de 1330 a Barcelona, atorgada pels Civader, mercaders barcelonins, a Pere ses Amaules, de Mallorca. Aquest haurà de recobrar 64 bales de cotó d'Amènia filat a Barcelona i 7 feixos grans d'ametllons enviats per Bemat Civader des de Mallorea a Flandes a la nau d'en Martí Coa de Castro; a més de 7 feixos grans d'ametllons i 8 bales de cotó filat d'Armenia, enviats pel mateix $i$ amb identic itinerari a la nau d'en Joan Bono de Castro; també per signar rebuts a Guillem de Sitges, llur soci a Flandes; i per rebre mercaderies $i$ ferne àpoques al regne de Castella (ACB, Guillem Borrell, M.1330, publicat per GARCIA-MADUREL, Societats, op.cit, $n^{0} 29$, pp.42-43).

${ }^{57}$ Vegeu en relació a aquest tema l'article de C. BATLE, La presenza degli stranieri a Barcellona nei secoli XII e XIII, a Dentro la ciltà. Stranieri e realtà urbane nell'Europa dei secoli XII-XVI, a cura de Gabriella Rossetti, Pisa, GISEM. Liguori Editore, 1989, pp. 87-110. Sobre els mercaders toscans, of M.T. FERRER MALLOL, Dues cartes en català des de Ciutadella a la companyia Datini de Mallorca (1405-1408), "Randa", 10, pp.81-97 i, de la mateixa autora, Intorno all 'assicurazione sulla persona di Filipozzo Soldani, nel 1399, e alle attività dei Soldani, mercanti fiorentini, a Barcellona, "Studi in memoria di Federigo Melis",II, Florència, Giannini Editore, 1978, pp. $441-478$. 
darrer com un mercat colonial, idea que ja fou rebutjada per Paulino Ira-

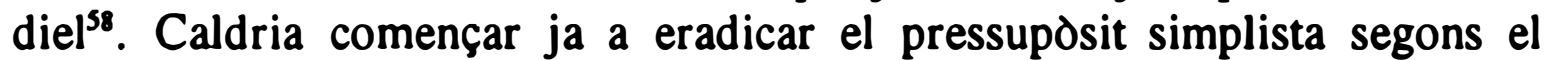
qual la prepotencia economica o de dominació ve representada per la sola aparició dels protagonistes en les transaccions documentades, o bé si només llur constant constatacio a les escriptures respon a d'altres factors.

Entre aquests, la necessitat d'aconseguir mecanismes de crèdit, circumstància que ens suggeriria una menor capacitat econdmica o/i la possibilitat d'emprar estrategies sense passar per legitimació notarial, com ho assoliren les principals empreses florentines ja als inicis del segle XIV. Malgrat tot, els dirigents o els delegats de les principals empreses toscanes apareixen a la darreria del tres-cents de forma important a les fonts notarials, especialment als contractes d'assegurances maritimes. La qual cosa no significa que no actuessin ben abans als ports catalans, ans al contrari, com ho demostren les repetides ordres d'expulsió d'italians, les primeres de les quals provenen de $1265 \mathrm{i}$ es van repetint fins al segle $\mathrm{XV}^{s 9}$. Aixd significa que, amb anterioritat a la implantació generalitzada de l'ús de les assegurances, alguns col.lectius, com pisans, florentins, genovesos, luquesos o d'altres, deixen poques constàncies escrites no perquè no comerciïn, sinó per la possibilitat de poder gaudir de recursos financiers d'altra mena.

Si ens fixem en els primers trenta anys del segle XIV, les referencies documentals ens parlen el 1314 de Manfredo de Ventimiglia i, el 1327, de Giovanni Bastini di Varagi, habitant de Savona ${ }^{60}$. Una societat de mercaders de Lucca actua a Valencia durant el perfode comprès entre els mesos de juliol del 1327 al gener del 1328: són Niccold Baratelli i Francesco Malgamagni, amb llurs factors, Villano Tigrini i Niccold Giacopo. Alguns corretgers valencians se'ls declaren deutors, efectuen diversos

\footnotetext{
${ }^{88}$ G. ROMESTAN, Els inercaders llenguadocians en el regne de València durant la primera meitat del segle XIV, a València, un inercat inedieval, València, Diputació, 1985, pp.175-263; P. IRADIEL, En el Mediterríneo Occidental Peninsular: dominantes y periferias dominadas en la Baja Edad Media, "Areas. Revista de Ciencias Sociales" (Múrcia), 1986, pp.65-77; i també C. CuAdRada, Credit i comers, op. cit.

${ }^{59}$ Vegeu A. de CAPMANY y de MONTPALAU, Meinorias históricas, sobre la marina, comercio y artes de la antigua ciudad de Barcelona, 2a ed. a cura d'E. Giralt i de C. Batlle, Barcelona, Cámara Oficial de Comercio y Navegación, 1962. Els documents representatius han estat analitzats per M.T. FERRER MALLOL, Els italians, op.cil.

${ }^{\infty} \mathrm{Al}$ primer d'ells, Pere Dusay, mercader barceloni, declara deure 2400 turonesos d'argent (AHPB, Pere de Torre 5-1, M.1314, f.130 v). El segon liquida una societat mercantil que formava amb Guillem Feliu, mercader de València (ARV, A. Lampart, P.10408, f.87).
} 
canvis de moneda amb mercaders de Narbona i Montpeller, com repetidament amb la companyia dels Ginestar de Valencia, mentre compren cordobans blancs a blanquers valencians, ad opus dicte societatis nostre ${ }^{61}$. Cinc anys més tard, és la societat florentina dels Peruzzi la que opera a València, concretament des d'abril a juny, potser coincidint o a continuació d'haver estat, juntament amb els Acciaiouli, creditors de la monarquia ${ }^{62}$. A la ciutat del Grau, Filippo Bonasegna, factor dels Peruzzi, contrau deutes a raó de canvis amb operadors de Narbona i Montpeller, alhora que compra anyins blancs a Martí d'Odrells, blanquer valencia ${ }^{63}$.

Són particularment interessants les dues formes darreres d'àpoques de canvi documentades el 25 i 28 de juny. El primer havia estat lliurat a Perpinyà i cancel.lat per Dalmau de Fluvià, mercader de Valencia, a la taula de Martf de Cedrells, canviador de la mateixa ciutat; el segon, rebut a la mateixa taula, fa referencia als diners pagats per Ramon Benedit i Joan Gai, mercaders i ciutadans valencians, a raó d'un canvi en moneda barcelonina que aquests devien a R. di Nando, de Florença, en concepte d'una quantitat de moneda en rals de França ${ }^{64}$. Mecanismes d'aquest tipus ens indiquen l'existencia d'un complex sistema d'estratègies financeres, en especial pel que fa a la possibilitat de girar credit en forma de numerari d'una plaça a l'altra per satisfer deutes entre els mateixos comerciants: un sistema ja ben modern, quasi de temps, diguem-ne, pre-capitalistes.

Tornant a l'anàlisi de les fonts, i per cloure aquest primer apartat, hem d' assenyalar que cal relativitzar convenientment la informacio a diferents nivells. No tan sols en la indispensable integracio de dades d'origen oficial i de caràcter privat, sinó igualment avaluant i combinant dins d'un mateix treball les aportacions més dispars, les indicacions de cròniques $\mathrm{i}$ literatura contemporània, els manuals de mercaderia, els petits indicis que potser ens poden brindar la iconografia o les imatges fornides pels cartularis. Sense oblidar les narracions dels viatgers i mercaders, reflectides de

\footnotetext{
${ }^{61}$ ARV, A. Lampart, P.10408, f.91v, 102, 119v-120, 151, 256v i 330.

${ }^{62} \mathrm{M}$. SÁNCHEZ MARTINEZ, Operaciones de los Peruzzi i Acciaiuoli en la Corona de Aragón durante el pritner tercio del siglo XIV, "Anuario de Estudios Medievales", 7 (19701971), pp. 285-311.

${ }^{63}$ ARV, A. Lampart, P.2971, f.2, 14-14v, 25v, 37.

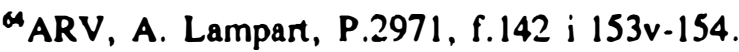


manera singular en llur correspondencia ${ }^{65}$, on l'expressió és lliure i sense constriccions legals o notarials. Un plantejament de tals característiques requereix, ben segur, una gran dosi de recerca, d'interpretacio, de metodologia i de crítica. Si féssim un estat sincer de la qüestio, caldria dir que els primers punts, els relatius a l'exhaustivitat de buidatge de les fonts i de la conseqüent comparança entre elles, encara no ha estat assolida en la seva totalitat. Pel que fa als segons, resten a l'horitzó dels projectes de futur. Malgrat tot, no creiem que aquesta aproximació actual trenqui amb cap dels objectius enunciats, sempre que es consideri una reflexió cenyida a la documentació recollida fins avui, i susceptible de millora en anar avançant en la investigació.

\section{ELS MOVIMENTS PORTUARIS: \\ EL PORT VALENCIÀ (1394-1396)}

Tal vegada algunes de les interpretacions del comerç catala baixmedieval ha estat exposada de manera massa parcial, sobretot pel que fa a la utilització de fonts documentals ja de per si restrictives. Qualsevol intent de reconstrucció de realitats és important que esmenti elements varis i contrastables entre ells; l'error es comet quan hom creu que, en un sol fons documental, s'hi troben totes les respostes. Fixem-nos, per exemple, en el cas que ja resulta prou conegut i fins i tot qüestionat, de l'ús de les sèries anomenades de "coses vedades". Les sortides del port de Valencia, només per a posar un exemple concret i reterit a l'any 1394, vindrien donades segons el gràfic núm. 1 (Vegeu Gràfic 1, al final de l'article).

Aquest gràic l'hem elaborat seguint les dades ofertes per José Hinojosa ${ }^{66}$, extretes dels registres de coses vedades del port valencià. Coincideix amb Orlandi pel que fa a la preponderància dels viatges vers l'illa, car ens indica un elevat nombre de sortides a Mallorca, el qual ressalta notablement entre les altres quantitats. A continuació vénen citats com

\footnotetext{
${ }^{65}$ Una mostra $\mathrm{i}$ les orientacions pertinents per a ampliar els suggeriments donats l'hem vista a la primera part d'aquest article. Sobre el llengüatge dels mercaders florentins operants a Catalunya, of C. CUADRADA, Del catcilà del Tres-cents, op.cit.

${ }^{66} \mathrm{~J}$. HinojosA, Algunos aspectos del coinercio valenciano en 1394, "Homenaje al Dr. D. Juan Reglà Campistol", I, València, Universitat, 1975. pp. 125-137.
} 
a ports de destinació Sevilla, Eivissa i Barcelona; seguits per Perpinyà, nord d'Àfrica, França; menys importants són els viatges a Genova, Tarragona i Flandes; en darrer lloc, Caller i Menorca. Aquests resultats s'han de matisar, pero. És veritat que les naus en direcció a Palma (188 viatges) quasi sextupliquen les següents dades, car cap a Sevilla comptabilitzem 34 viatges, cap a Eivissa 30 i cap a Barcelona 27. Malgrat tot, no hi ha seguretat que l'objectiu final d'aquests trajectes fos realment Mallorca, perque des d'allf partien cap al Magreb, com ho demostren les sortides del port de Mallorca el mateix any, segons l'estudi de Francisco Sevillano Colom ${ }^{67}$ dels llibres d'ancoratge (Vegeu Gràfic núm. 2, al final de l'article).

La diversitat d'apreciacions prové d'emprar fonts documentals de caire diferent, pero hi ha també elements de tipus metodologic que cal explicitar. D'una banda, no sabem si els oficials que registraven les entrades i sortides anotaven l'últim port on els vaixells havien recalat, pel que fa als que es dirigien al Grau. Si es feia aixi, no podem estar segurs de si el viatge havia estat més llarg o no, de la mateixa manera que no podem dir que les embarcacions amb una destinació concreta -l'anotada al llibre de coses vedades-fos el punt final del trajecte. El valor d'aquestes dades és el d'oferir un moviment portuari intens $i$ una relació predominant ValenciaMallorca, tant d'anada com de tornada, a més de la multiplicitat de rutes des del Grau.

D'altra banda, és necessari assenyalar que la fiabilitat de la font és molt minsa, tenint en compte el mateix concepte amb el qual s'elaboren aquests registres. La sol.licitud de llicència de comerç de productes prohibits força vegades no es presentava i aixi cometien els mercaders un frau directe, aspecte que va posar en evidencia Josep Trenchs ${ }^{68}$. Haurfem de sumar-hi els intents continuats de frau indirecte, a les declaracions de destinacio fictícia, amagant-ne la veritable, com succeeix amb les dades d'arribada a les Illes, Sevilla o Caller (des d'on podien dirigir-se amb facilitat a les places del nord d'Àfrica occidentals $\mathrm{i}$ orientals). D'altres localitats citades com a punt final del viatge, tals com Barcelona, Perpinyà, França en general o Genova, tenen també un märge de possible error, més accentuat en el cas de la ciutat comtal, on podien anar els vaixells a carregar més mercaderies vedades $\mathrm{i}$ continuar el viatge vers altres llocs. Flandes, amb

\footnotetext{
${ }^{67}$ F. SEYILLANO COLOM, Mallorca y Valencia, op.cit.

${ }^{68} \mathrm{~J}$. TRENCHS, De Alexandrinis, op.cit.
} 
seguretat, era una destinacio final, mentre que Tarragona possiblement no era més que una escala.

Pel que veiem al gràfic $n^{0} 1$, des del port valencià les rutes seguides són ben diferenciades i la seva projeccio internacional era força notable. Deixant de banda les interrelacions amb les Balears, les vies maritimes ens porten a la constatació de les àrees atlàntica (Sevilla, Flandes) i mediterrània (Sardenya, sud francès, Genova i nord d'Àfrica), a més de la navegacio de cabotatge resseguint la costa catalana.

\section{ELS MOVIMENTS PORTUARIS: \\ Barcelona, mallorca i València (SEGLES XIII-XV)}

Si les cartes comercials ens ofereixen dades bastant riques per a mesurar la quantitat d'entrades i sortides de vaixells en un port concret $i$ per a un perfode temporal curt, les informacions oferides per aquest tipus de font contenen en si mateixes alguns inconvenients. Primer, la parcialitat dels observadors, ja que els operadors economics italians es fixaven especialment en les naus que els interessaven de forma particular, sense voler en cap moment donar una relacio exhaustiva de la totalitat del moviment portuari. Segon, són informacions referides a uns quants anys i, per tant, extremadament sincroniques.

Al contrari, utilitzant les indicacions fornides pels documents conservats als protocols notarials, podem oferir una visio de la realitat historica que, malgrat que no parteix d'una base quantitativa completa, ens facilita el suggeriment de les tendencies generals, i aquestes en un arc de temps molt més ampli. Per tal de reflectir-les, hem recollit quasi uns tres-cent documents (287), de manuals de notaris i escriptures en pergamf conservades en diferents arxius de Barcelona, Mallorca i Valencia ${ }^{69}$, per al perfode com-

\footnotetext{
${ }^{60}$ De Barcelona: ACA, fons de Jaume I i Registres d'Hisenda 4, 9, 11, 12, 16, 18, 19, 21; ACB, fons "Diversorum" A i C, i dels notaris Bernat de Vilarrúbia, Guillem Borrell i Guillem Canyelles; i AHPB, els fons dels notaris Pere Portell, Pere Torre, Guillem Borrell, Llorenç Canals, Pere Folgueres, Pere Olm, Pere Folgueres, Jaume Ferrer, Pere Borrell, Guillem de Sant Hilari, Pere Martí, Jaume Just, Ferran Gombau, Pere Martí, Perran Relat, Bemat Nadal, Amau Lledó, Jaume Nadal i Tomàs de Bellmunt. De Mallorea: el fons de Lletres Rebudes i del "Lou dels Pizans". De Valencia: els fons dels notaris Aparici Lampart, nutal 1040, profo-
} 
près entre els inicis del segle XIII (1213) i els inicis del XV (1412). És a dir, que possibiliten una perspectiva diacronica. Els documents emprats son de tipologia vària: comandes marítimes, contractes d'assegurança, nòlits, enrolaments, $i$ algunes referencies parcials de registres de duanes i pagament d'impostos.

Pel que fa a la quantitat de documents en relació a la cronologia, els percentages són el següents:

$\begin{array}{ll}\text { CRONOLOGIA } & \text { DOCUMENTS } \\ -1213 / 1225 & -1,39 \% \\ -1226 / 1250 & -1,39 \% \\ -1251 / 1275 & -9,40 \% \\ -1276 / 1300 & -9,05 \% \\ -1301 / 1325 & -21,25 \% \\ -1326 / 1350 & -20,20 \% \\ -1351 / 1375 & -17,07 \% \\ -1376 / 1400 & -11,14 \% \\ -1401 / 1412 & -9,05 \times\end{array}$

cosa que significa que la major part de la documentació (el 69,66\%) és la corresponent al segle XIV. És conegut que com més ens allunyem en el temps les dades escrites esdevenen proporcionalment més escasses, i aquest és el motiu de les poques referències de la centúria anterior. Motiu, aixd no obstant, que no podem extrapolar al petit percentatge dels anys 1401-1412, ja que al segle XV la documentació es cada vegada més i més abundant. L'explicació prové d'haver centrat la recerca arxivistica en especial al trescents, començant per la primera meitat, perque aquests cinquanta anys encara són mal coneguts $i$, a més, per poder jugar amb uns altres tipus de fonts, com la documentació datiniana, per a la resta del perfode, fins al 1412. Una darrera advertencia, abans de passar a l'anàlisi de les dades documentals, és la d'assenyalar que, ateses les caracteristiques dels contractes notarials recollits, podem avaluar amb molta major proporció les sortides dels ports i no tant les entrades. Aixo és degut al fet que la contractacio de comandes, assegurances i nolits es feia abans d'emprendre el viatge, des del lloc de partida. Tenint en compte aquesta salvetat, dissenyarem les principals rutes de cadascun dels ports segons l'evolució cronologica.

El port de Barcelona al segle XIII mostra un eloqüent dinamisme i una intensa activitat internacional, tal com ho podem comprovar al gràfic

col 2838, protocol 2757. Algunes dades provenen dels notaris B. di Citella i R. Rusticis de l'Archivio di Stato di Pisa, ASPi. 
núm 3 (Vegeu Gràfic 3, al final de l'article), en el qual apareixen, en primer lloc, les places nord-africanes, amb 21 viatges. Les destinacions són Bugia, Bona, Tunis, Alexandria, Alcúdia, quan s'especifiquen ${ }^{\text {to; }}$ d'altres prenen el nom genèric de Barbaria ${ }^{71}$; a voltes s'indiquen les etapes del trajecte: de Barcelona a Sicflia o Tunis, a Denia i a Barbaria o Tunis, a Espanya i a Barbaria. Com tambe succeeix en algunes de les arribades: des de Tunis a Aigües Mortes i a Barcelona ${ }^{2}$. En sĕgon lloc es situen les destinacions d'Ultramar, tambe citades sense concretar, en alguns casos, i amb indicació particular en uns altres: Sant Joan d'Acre, Romania, Xipre, Armenia, Candia ${ }^{7}$. En tercer lloc trobem la ruta de les Illes -Sicflia, Sardenya-, després la de Provença -Marsella, Aigües Mortes, Montpeller, Colliure- seguida dels viatges a Mallorca i Valencia. Solament una menció ens parla d'una ruta de clar cabotatge: Barcelona-Sitges-La Geltru-Tarragona; mentre que una altra es dirigeix a Genova ${ }^{74}$.

A la primera meitat del tres cents, els interessos internacionals dels vaixells sortint de la platja de la ciutat comtal varien, com ho podem comprobar al gràic núm. 4 (Vegeu Gràfic 4, al final de l'article).

Els canvis més significatius són, sens dubte, l'increment dels viatges amb objectiu a Sicflia i Sardenya ${ }^{75}$, i la gran disminucio de naus en direccio al Magreb $^{76}$, que de ser la ruta preferent al segle XIII passa a ocupar un lloc molt menys important durant aquests anys, segurament

${ }^{20}$ ACB, Diversorum C, $n^{\circ} 132, n^{0} 1258, n^{0} 2029, n^{\circ} 2658, n^{\circ} 799, n^{\circ} 2051, n^{0} 1950$ $n^{\circ} 2125, n^{\circ} 2902, n^{\circ} 361, n^{\circ} 638, n^{\circ} 3017, n^{\circ} 718$; Bemat de Vilarrúbia, M.1295, f.56-57.

${ }^{1}$ ACB, Diversorum C, $n^{0} 2901, n^{0} 2589, n^{0} 199, n^{0} 2902, n^{0} 254, n^{\circ} 512, n^{0} 359$.

${ }^{n} A C B$, Diversorum C, $n^{0} 2125, n^{0} 254, n^{0} 361, n^{0} 512, n^{0} 760$.

${ }^{73}$ ACB, Diversorum C, $n^{0} 154, n^{0} 102, n^{0} 485, n^{0} 3252, n^{\circ} 2892, n^{0} 635, n^{0} 2760, n^{\circ}$ 984; Bernat de Vilarnibia, M.1292, f.31; AHPB, Pere Portell, M.1299, f.2, 5, 7, 12.

74Illes: ACB, Diversorum A, $n^{0}$ 363; Diversorum C, $n^{0} 2829, n^{\circ} 1829, n^{0} 2125, n^{\circ}$ 3176, $n^{0} 2763, n^{0} 1812, n^{0} 429$; Bemat de Vilamúbia, M.1295, f.96. Provença: ACB, Sant Sever, $n^{0}$ 3158; Diversorum C, $n^{\circ}$ 753, $n^{0}$ 134; ACA, Jaume I, $n^{\circ}$ 67. Mallorea: ACB, Diversorum C, $n^{\circ} 3186, n^{\circ} 2034, n^{\circ} 632$. Valencia: ACB, Diversorum C, $n^{\circ} 989, n^{\circ} 460$, $n^{\circ}$ 992. Tarragona: ACB, Diversorum C, no 1381. Genova: ACB, Bemat de Vilarrúbia, M.1292, f. 16 .

${ }^{75}$ ACB, Diversorum C, $n^{0}$ 3806; ASPi, B. de Citella, f.10-11 i 146; AHPB, Pere de Torre 5-1, f.2, 37, 11, 17, 27, 40, 43, 67-69, 113; Pere de Torre 5-2, f.25, 37, 36, 44, 92, 129 , 134, 140; Pere de Torre 5-3, f.35, 48, 56, 57, 64, 66; ACB, Guillem Borrell 8-1, f.111; AHPB, Llorenc Canals 11-1, f.20, 34, 39, 47; Jaume Ferrer M.1349, f.4, 42.

${ }^{76}$ Barbaria: ACB, Matoses, perg.17 (b). Alexandria: AHPB, Pere de Torre M.1314; Jaume Ferrer 17-1, f.33. Trípoli: AHPB, Pere de Torre M.1314, f.80. 
perque serà Mallorca qui prendrà, cada vegada més, el protagonisme del comerç amb el nord africà. Els trajectes a Ultramar ${ }^{n}$-Xipre, Romania, Barut, Rodes- augmenten; en tercera posicio trobem els ports provençals $^{\text {sh }}$-Colliure, Aigües Mortes, Marsella, Narbona-. Amb menors proporcions, viatges a Mallorca i Menorca, costa valenciana - Valencia, Alacant i Múrcia-, centres italians -Genova i Venecia- i litoral català-Pals, Tarragona, Roses, Tortosa-. Menys representatius encara, dues anades a Sevilla.

Aquests resultats, pero, són succeptibles d'observacions, especialment en relacio a les embarcacions procedents de la ciutat comtal a Palma. Si ens fixem en les dades ofertes pels registres d'Ancoratge, reflectides al gràfic núm. 5, ens indiquen una proporció molt alta de barcelonins, la més elevada, al port mallorqur'. (Vegeu Grafic 5, al final de l'article).

Pel que fa a les sortides del port del Grau a aquesta primera meitat del tres-cents, tenim la informacio que es pot observar al grafic núm. 6 (Vegeu Gràfic 6, al final de l'article).

Tal com hom pot comprobar, la destinació més rellevant és la del litoral magreb ${ }^{p o}$-Alcúdia, Honein, Mostaganem, Tunis-. Una característica de valor és la de trobar documentats els viatges sencers, per exemple: Valencia-Mallorca-Alcúdia; Valencia-Morvedre-Mallorca-Barbaria; Valencia-Alcúdia-Barcelona; Valencia-Morvedre-Honein; Valencia-AlacantMostaganem... Seguidament, les interrelacions amb Mallorca i Sardenya, a continuacio Barcelona, en menor grau les mantingudes amb Genova i Sevilla (igual proporcio, per al mateix perfode i lloc final, que les documentades des del port de Barcelona, per a aquesta última plaça). Amb quantitats mínimes (1), es comptabilitzen viatges a Pisa i a Brest.

Tornant al port de Barcelona i referint-nos ara a la segona meitat del segle, cal en primer lloc tenir en compte els moviments d'entrades $i$

${ }^{n}$ AHPB, Pere de Torre M.1314, f.95-96, 119, 126, 125; Pere de Torre 5-2, f.27, 28, 105, 151, 157, 162; Llorenc Canalo 11-2, f.36, 71; Pere Folgueres 12-1, f.170; Pere Olm 139, f.23; Pere Folgueres 12-2, f.68; Pere Folgueres 44-45, f.68; Jaume Ferrer M.1349, f.51, 97-99; Jaume Ferrer 17-5, f.7, 14, 109. f.117.

${ }^{n}$ AHPB, Pere de Torre 5-1, f.56, 101; Pere de Torre 5-2, f.78, 102; Pere Olm 13-2,

${ }^{79}$ Elaboreda segons l'aportació de F. SEviulano CoLOM, Mallorca y Valencia, op.cit.

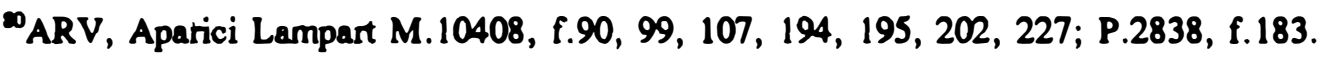


sortides referides a l'any 1357 , realitzades per Maubert ${ }^{81}$ (vegeu el Grafic núm. 7, al final de l'article), on les relacions més intenses, tant de viatges d'anada com de tornada s'efectuen entre el port barcelonf $i$ el valencia, i on podem comprobar que el trafic de cabotatge al llarg de la costa catalana es predominant.

Si considerem la documentacio notarial fins al 1412, obtenim els resultats que s'expressen en el Gràfic núm 8 del final de l'article, en el que novament s'hi observen canvis de tendencia: la preponderància de destinacions es dirigeixen vers Genova, malgrat les dificultats consegüents a l'estat de guerra oberta entre ambdos estats -cal tenir en compte, pero, que algunes d'aquestes dades provenen de registres de duana i poden defomar el total de la informacio amb un marge d'error no quantificable a l'estat actual de la recerca-. A continuacio, la ruta d'Ultramar que recull un nombre major de sortides en referencia a la primera meitat de segle, seguides de les transaccions amb Valencia, després amb Sardenya i Sicflia, continuades pels vaixells amb direcció al nord d'Àfrica (només 6), quatre cap a Lisboa, i amb mínimes mencions (1 sola vegada) els viatges a Venecia, Provença, Blanes, Mallorca i Tarragona. El matís que cal fer d'aquest resultat és la continuïtat de la ruta d'Ultramar, extremadament mantinguda, la perdua de relacions amb els ports del litoral provençal i l'intent d'obertura vers Portugal, mentre que decau relativament l'interes envers Sardenya o Sicflia, guanyat per la ruta cap a la costa ligur.

Si passem a les informacions brindades per la correspondencia dels operadors italians operants a casa nostra a la darreria del segle XIV, el moviment portuari pren dimensions força més amplies, per no dir quasi universals per al món de l'epoca. D'un buidatge de 200 cartes comercials procedents de la literatura datiniana, amb informacions sobre rutes de trafic mercantil ${ }^{82}$, relatives als anys corresponents al perfode comprés entre

\footnotetext{
"C.G. MAUBERT, Le mouvement du port de Barcelone pendant l'hiver 1357, "Anuario de Estudios Medievales", 10 (1989), pp. 659-688.

${ }^{8}$ Es troben als registres següents: ASP, AD $n^{0} 1171, n^{0} 931, n^{\circ} 187, n^{\circ} 377, n^{\circ} 184, n^{\circ}$ $431, n^{0} 633, n^{0} 705, n^{0} 1008, n^{0} 756, n^{\circ} 757, n^{\circ} 758, n^{\circ} 748, n^{0} 1128, n^{0} 1085, n^{0} 754$, $n^{0} 324, n^{0} 749, n^{0} 886, n^{0} 1406, n^{0} 634, n^{0} 666, n^{0} 434, n^{0} 1078, n^{0} 1003, n^{0} 705, n^{0}$ 979, $n^{\circ} 851, n^{\circ} 645, n^{\circ} 1048, n^{\circ} 887, n^{\circ} 1082, n^{\circ} 1006, n^{\circ} 1050, n^{\circ} 441, n^{\circ} 1073, n^{\circ} 881$, $n^{\circ} 1053, n^{\circ} 1072, n^{\circ} 647, n^{\circ} 865, n^{\circ} 648, n^{0} 999, n^{\circ} 1112, n^{\circ} 891, n^{0} 984, n^{\circ} 528$ i $n^{\circ}$ 1081. L'aparent desordre numèric es justifica per haver extret el llistat documental basat en la cronologia de les dades aportades.
} 
1371 i 1410, hem aconseguit 478 citacions de punts d'origen, de recalat i de destinació de naus. Pel que fa referencia als Països Catalans, deixant de banda si els vaixells entren o surten del port, la ciutat més anomenada és Barcelona, amb un 23,6\% del total, seguida de Mallorca amb un $10,25 \%$, Valencia $(7,7 \%)$ i altres ports $(6,9 \%)$. D'aquests resultats, cal fer-ne algunes consideracions: en primer lloc, que la preeminencia d'atenció concedida a la ciutat comtal per part dels agents datinians, fins i tot quan semblava quasi superada per l'emergencia del port valencià, és quelcom ressaltable $i$ caldrà saber-ne segurament el perque. Evidentment, no fou, en aquells anys, ni per la seva potencia economica -recordem les fallides de les banques privades, per exemple- ni per la primacia de que podria gaudir dins d'una xarxa comercial concreta com la de la companyia Datini, els mateixos anys, radicant-se a la ciutat del Grau. Esperem aconseguir a través de les nostres recerques actuals a l'Arxiu Datini, de Prato, llum sobre aquest aspecte, aixi com d'altres que encara en resten dins l'ombra, el dubte i la pregunta.

En segon lloc, el resultat de voler copsar els moviments d'entrada i sortida de ciutat de Palma ens sembla molt més facil d'entendre. Al cap i a la fi, els mercaders florentins, com abans ho havien intentat els pisans $i$ els genovesos, varen trobar a l'illa de Mallorca un veritable fre per a les seves intencions d'expansió mercantil vers el nord d'Àfrica. El seguiment de les embarcacions en direcció als regnes musulmans no era, doncs, cap feina inútil, al contrari. Més curiós resulta la comprovació que segueix, car pensàvem que la ciutat de Valencia podria haver superat i tot el percentatge de Barcelona. Pero segons les nostres dades no succeeix d'aquesta forma, ja que Valencia ocupa el tercer lloc amb un minim 7,7\%, com ho hem dit més amunt. En tercer lloc, la incidencia en la voluntat de fixar les transaccions ve referida a d'altres ports dels regnes litorals de la corona. Comptada a nivell de tants per cent de manera independent $i$ sense incloure-la dins del grup "d'altres ports", Tortosa té un protagonisme força important, darreta les tres capitals abans esmentades, amb un 2,5\% dels viatges comptabilitzats. En relacio als centres de menor incidencia a les fonts considerades, cal apuntar Peníscola, Xàtiva, Menorca, Eivissa i Escatron, a més de les referencies a Catalunya, sense especificacio de lloc concret.

És ben clar que l'aparició de llocs com Tortosa i Peníscola responen a interessos del mercat de la llana, com també aixi Escatron, port fluvial de l'Ebre. És important fer notar alguns recorreguts: el 1390, de 
Tortosa a Barcelona fins a Genova ${ }^{83}$; dos anys més tard, de Tortosa a Barcelona fins a Pisa ${ }^{84}$; el mateix any, de Barcelona a Peníscola amb destinació Pisa i, des de Valencia, seguint el mateix camps; el 1393, de Peníscola a Barcelona vers Pisa ${ }^{86}$; tambe el 93, de Peníscola a Genova ${ }^{87}$; el 1394, de Tortosa a Pisa i Genova ${ }^{88}$; el 95 de Valencia a Tortosa cap a Pisa ${ }^{99}$. Els itineraris poden fer-se més complexos, no obstant aixo. Per exemple, el mateix any, documentem un trajecte de Barcelona a Mallorca, d'alla a Menorca, amb l'objectiu de Peníscola ${ }^{90}$; malgrat no tenir constatacions de moviments posteriors, creiem que no seria massa agossarat suggerir que la mateixa nau continuà el viatge vers la costa ligur. Del mateix any 95 les cartes comercials ens aporten més dades sobre trajectes realitzats des de Menorca a Peníscola, després a Tortosa i vers Barcelona ${ }^{91}$; la mateixa observació feta abans seria valida en aquest cas. A partir de l'any següent, el 1396, les rutes semblen engrandir-se: apareix repetides vegades Venecia, des d'on surten naus i galeres que van a Mallorca i a Peníscola; o des de Venecia a Mallorca, Valencia i Tortosa; o des de Venècia a Valencia, Peníscola i Tortosa ${ }^{22}$. Tal volta, d'aixo, hom en podria deduir un cert interès dels venecians en el comerç de la matèria primera del Maestrat, pero pensem que més val deixar-ho a nivell d'hipdtesi, sense treure'n conclusions precipitades. El que sí que sembla un fet cert i creỉble és el de documentar el trajecte de dues barques d'Escatron a Tortosa i, a més, d'assegurar quasi sense temor d'errar el transport de llana ${ }^{93}$.

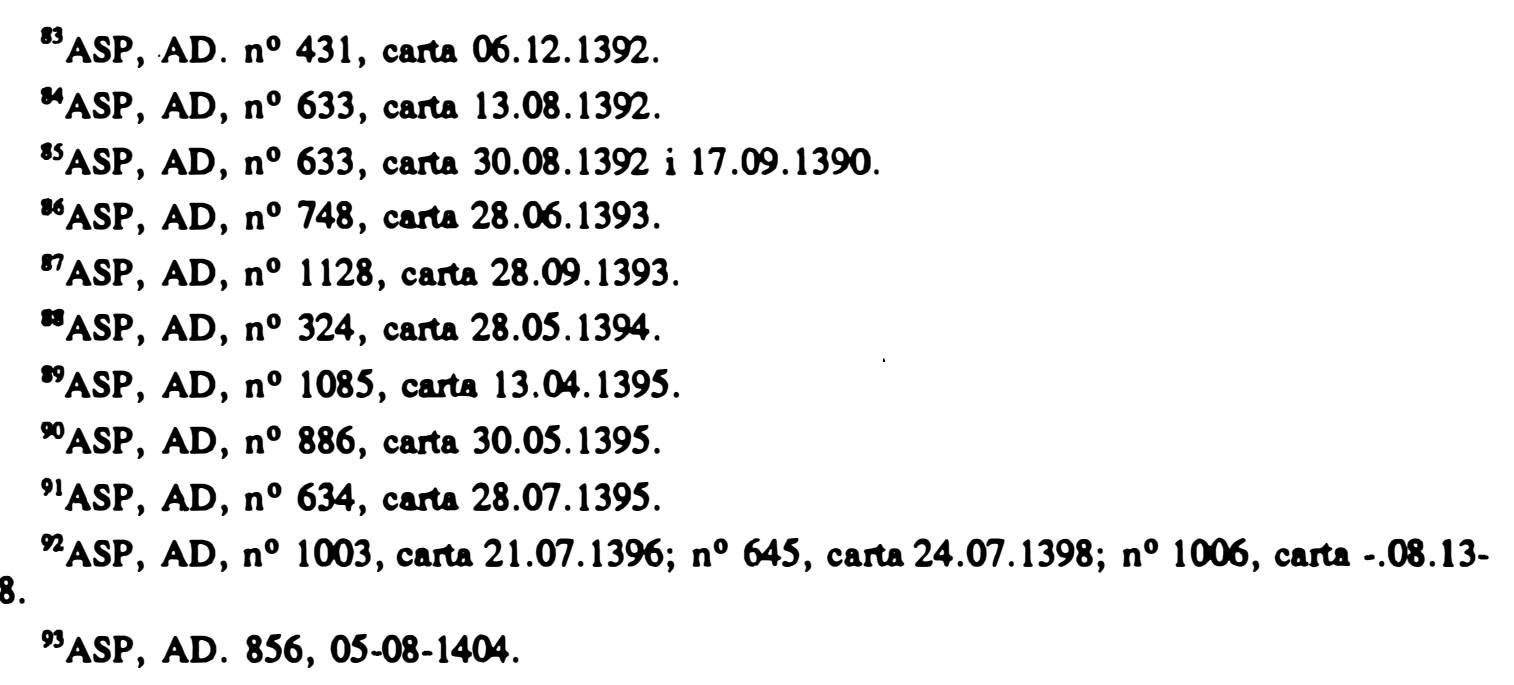


Un altre caire prenen d'altres rutes, igualment protagonitzades per Venecia, pero en relació a Menorca o Eivissa, datades majoritàriament, segons els documents que hem analitzat, a partir dels darrers anys del trescents, informacions que coincideixen amb les ja constatades per Giampiero Nigío i per Angela Orlandi, i en llurs respectives tesis de llicenciatura ${ }^{24}$. Pel que fa al nostre buidatge, a partir dels primers anys del segle XV apareix Venècia repetides vegades a les Balears, en vaixells que es dirigeixen vers Anglaterra o Flandes, alguns fent port a Valencias. També a cavall del tres i quatre-cents s'intensifiquen els traffics, alhora que l'atenció dels operadors economics florentins es dirigeix cada cop de forma més insistent vers l'Atlantic: Flandes-Cartagena-Genova; Genova-L'Escluse-Ancona; Barcelona-L'Escluse; Múrcia-Flandes; Barcelona-Damasc; Flandes-Cartagena-Eivissa-Piombino; Flandes-Mallorca; Venècia-Mallorca-Flandes ${ }^{*}$.

Hem de dir també que les referencies documentals que aquesta mostra comporta ens donen per al Llevant un 4,18\%; el Magreb, només un $1,04 \%$; per a Genova, un $11,7 \%$; per a Pisa, un $10,6 \%$; per als ports de la Provença, un $1,4 \%$; per a les Illes -Sicflia, Sardenya-, un 1,4\%; per a Flandes, un 6,6\%; per als ports castellans -Sevilla, Galícia, Cadiç, Cartagena, Múrcia-, un 3,3\%; per a Venecia, un 2,7\%; i finalment, un apartat que hem intitulat "altres", amb un percentatge d'un $2,3 \%$, inclou ports italians de menor entitat -Motrone, Livorno, Piombino- els quals ens apareixen a partir de l'any 1398 en endavant ${ }^{97}$. Fent referència a Barcelona, el 1371

${ }^{94}$ Vegeu mes amunt, pàg. i nota 21 .
${ }^{95}$ Com per exemple ASP, AD, no 647, carta 19.09.1403.
${ }^{96}$ ASP, AD, n' 648, carta 28.11.1404; n' 999, carta 08.03.1406; n' 1112, carta 26.03.1406; $n^{\circ}$ 999, carta 17.07.1406; $n^{\circ}$ 891, carta 27.04.1407; $n^{\circ}$ 528, carta 22.04.1410.

${ }^{97} \mathrm{~L}$ 'emprar ports de menor entitat o tal volta alternatius ha estat considerat per $M$. TANGHERONI, Trasponti navali e comnercio marittimo nell'Italia del Quattrocento, "Revista d'Història Medieval", 3 (1992), pp. 27-53. Veure tambe M.TANGHERONI i O. VACCARI, L'osservatorio datiniano di Livomo e la navigazione mediterranea tra Tre e Quattrocento, "Convegno 'L'uomo e il mare'", Getnova, juny 1992 (en vies de publicació). Una dada que ens sembla d'interès prové de les mateixes explicacions que donen els mercaders italians en relació a emprar un port o un altre. Bastant suggestives hem trobat les exclamacions de la societat dels Carri de Bolonya, el 1401, en una carta dirigida a la companyia Datini de Pisa: "dite che chosti z radopiate le ghabele e che chuale paghava seta l'avonera 8.1 per fiorino pagha ora 8.5 senza oro, e chon oro e argento 8.15 fiorino, diche vi diciamo z una schifeza chosa, per tale che mai vi si potrd uxare, e noi abiammo uno fardelo per mandare a Barzalona che l'aremmo mandato per charichare in su in Charbone diche per chaxone de detta ghabela cresuta non lo mandarnmo, serae meglo mandare da Mutrone o da Vinegia e asai meno spese, diteci come la cosa procede" (ASP, AD, $n^{\circ} 441$, carta 01.11.1401). La documentació d'aquesta companyia ens mostra, amb molta assiduîtat, la utilització del port de Motrone, abans i després de la 
datem dues entrades al port, provinents d'Alexandria i de Barut. El 84, els corresponsals datinians consignen transaccions de Valencia a Aigües Mortes, i tambe des de Porto Pisano a Barcelona, Tortosa i Mallorca. Per a l'any posterior apareixen dues entrades més al port de la ciutat comtal, ambdues procedents d'Ultramar (des de dos recorreguts diferents: Alexandria-Barut-Barcelona; Alexandria-Tunis-Sichlia-Barcelona) ${ }^{\text {pe }}$. Malgrat aixd, cal advertir que les informacions més fiables serien les dels anys que la companyia Datini operà a la ciutat i als Països Catalans, o també les informacions fornides pels mercaders amics en anys immediatament anteriors, car aquestes es tenien, per força, molt en compte abans de procedir a la instal.lacio d'una delegacio mercantil. Si prenem com a punt base el perfode compres entre el $1391 \mathrm{i}$ el 1401 -dates que fixem només amb dependencia del nostre buidatge a l'Arxiu Datini-, podem arribar, amb l'ajuda dels fons consultats, a la constatacio d'un trafic molt intens entre Barcelona i Pisa i Genova, mentre que des de Valencia els vaixells es dirigeixen sobretot cap a Flandes, com ho fan tambe els que recalen a Mallorca. Des de Mallorca hi ha igualment la ruta vers el Magreb, com ho fan algunes embarcacions valencianes. En concret, les dades que tenim mostren pel 1391 una trajectoria majoritaria vers Genova i Pisa, des dels ports catalans. Aixo es repeteix l'any següent, amb la variant de trajectes fins a Venecia, amb origen des de Barcelona i parada a Mallorca ${ }^{99}$. Les relacions entre la costa toscana i ligur continuen essent força importants durant els anys següents, mentre van apareixent també les constatacions de les grans rutes, fins a Flandes, vers Romania.

\section{LA TIPOLOGIA DELS VAIXELLS}

A les cartes comercials datinianes les embarcacions que apareixen són majoritàriament naus, encara que també hi trobem coques,llaüts,llenys, fustes, barques, galiotes i galeres. Aquestes últimes sempre vénen citades

pujada dels pagaments de la gabella pisana. 385.

${ }^{98} \mathrm{ASP}, \mathrm{AD}, \mathrm{n}^{\circ} 1171$, carta 07.11.1371; $n^{\circ} 377$, carta 19.09.1384; n' 431, carta 15.09.1-

${ }^{99} \mathrm{ASP}, \mathrm{AD}, \mathrm{n}^{0}$ 633, carta 13.08.1392. 
amb referencia a patrons venecians $i$ en viatges vers Flandes ${ }^{100}$. Pel que fa a la percepció que tenien els coetanis del tonatge i també de la gradació de la tipologia de les naus, em sembla ben interessant considerar una venda de l'anomenada "impossicio de les terres cismarines" a Perpinyà, el 1334, realitzada per Joan Voll i Pere Aulomar, comerciants i rectors de l'impost, a favor de Bernat Egidi, Arnau Jaufret, Guillem Bonet, Joan Calvet, Guillem Llop, Bernat Boffat i Joan Guerau, tots mercaders de la ciutat ${ }^{101}$. El document especifica que s'haurà de pagar segons la importància. Consta que els vaixells "que vagin o vinguin d'Ultramar" si són naus o coques abonaran, per cada coberta, 12 lliures i 15 sous; els llenys de dues bandes, 3 lliures i 8 sous; els llenys grossos d'una coberta, 6 lliures. Les embarcacions que efectuïn viatges a Caller, Tunis, Sicflia, Venecia, Pisa, Nàpols, Hispania, Berberia, si són naus o coques, 4 lliures i 5 sous per coberta; si llenys de dues bandes, 2 lliures, 2 sous i 6 diners; si llenys grossos d'una coberta, 3 lliures i 8 sous; si galeres o tarides, 3 lliures i 8 sous. Per als trajectes d'anada o vinguda de Valencia, Catalunya, Mallorca o les illes, si són naus o coques, 2 lliures, 2 sous i 6 diners; si llenys de bandes o barques armades de port de màxim 500 quintars, 8 sous; si llenys grossos d'una coberta de 500 quintars, 10 sous; si són barques Idescobertes de més de 100 quintars, 5 sous $i$, de menys, 3 sous. En relacio als vaixells de menor entitat declaren: "Item, tot lahut per poch que sia, d'on que vengua o vaia paguarà 6 diners"; els llauts de 25 a 30 quintars, 1 sou; i les barques i llaüts de 40 a 50 quintars, 2 sous.

Amb aquest exemple podem veure, doncs, no solament a quant pugen els drets fiscals d'entrada o sortida al port de Perpinyà, sinó igualment l'enumeració tipologica i l'adequació del volum de les naus a rutes concretes, a més de la jerarquia d'aquestes. En primer lloc hi ha Ultramar, segueix l'espai mediterrani central, finalment l'àmbit dels Països Catalans.

\footnotetext{
${ }^{100}$ Sobre el volum dels vaixells i la construcció naviliera cfr. M. TANGHERON1, op.cit; A. RIERA, La construcció naval a Catalunya a les vespres dels grans descobriments geografics (1350-1450), "Revista d'História Medieval", 3 (1992), pp. 55-78.

${ }^{101}$ ADPO, serie B, 1.B.14.
} 


\section{ALGUNES REFLEXIONS I VIES D'ANÀLISI DE FUTUR}

He presentat aquesta analisi exposant alguns dels resultats de la recerca fins enguany, seguit de consideracions que provenen del meu treball arxivístic, no pas de manera capritxosa i/o més o menys elucubrant, menys encara amb intencio de formular tesis o models. En realitat, aquesta és una forma d'apropar-nos als estudis anteriors i a les dades de la investigació recent. L'objecció que hom podria fer a aquesta exposicio seria la de no haver teixit la trama, des d'aquest moment, de tots els elements en joc. M'hi he resistit per coherencia, car si alguna cosa comporten els estudis del comerç baix-modieval, al meu entendre, és la seva gran complexitat i la seva dificultat en el tractament de dades diverses. Penso que la postura més prudent és la de deixar ara per ara les recerques al nivell en el qual es troben, sense voler anar més enllà del que l'estat de la qüestió permet. A més, malgrat saber que mai aconseguirem arribar a la totalitat de la informació de l'epoca, el que s'hauria d'intentar seria combinar totes les dades que, fins ara i al màxim d'arxius, ens han pervingut. Per tant, mentre no tinguem una base de dades prou completa, més val no avançar resultats parcials amb pretensions de resultats absoluts, car podrien distorsionar la visió general del periode. Per assolir aquest objectiu, es fa més que necessari el treball en equip, format per investigadors de diferents nacionalitats $^{102}$.

Aquestes paraules no signifiquen, pero, el rebuig o la negacio de moltes investigacions que els medievalistes han portat a terme, ans al contrari. Tesis com les de Claude Carrère, Mario del Treppo o Jacqueline Guiral-Hadziiossif són d'indubtable qualitat; en el cas dels dós primers, $s$ 'ha de reconeixer que continuen com a models i que poques veus s'hi han

\footnotetext{
${ }^{102}$ És el que, per analitzar l'evolució del comerç castella als segles XIV-XVI, ha proposat Hilario Casado, investigador principal d'un projecte amb aquest títol finançat per la Junta de Castilla-Loón, de la qual formo part, juntament amb investigadors holandesos, francesos, catalans i castellans. Així mateix, segueix aquesta intenció l'ampliació del programa a un segon projecte, dina del programa franco-espanyol en Ciències Socials i Humanes entre el Centre National de la Recherche Scientifique (CNRS) i la Dirección General de Investigación Científica y Técnica (DGICYT), amb el tútol "El comencio franco-español en los siglos XIV, XV y XVI", amb referència PFECS93-0015, en el qual tambe col.laboro.
} 
alçat en contra ${ }^{103}$. De tota manera, la visió segons la qual es van elaborar és, per als primers, clarament barcelonocentrica, mentre que la darrera es centra exclusivament en el port valencià; la qual cosa significa que encara estem mancats d'una visió de conjunt, en què es puguin fer ressaltar les diferencies pero que, alhora, mostri les intencionalitats comunes. Aquest fet s'uneix a molts altres treballs parcials, amb un caràcter prevalentment "localista", on l'apropament temàtic es revela sovint superficial i concentrat en la constatacio del fenomen comercial, sense examinar-ne causes o conseqüencies. Ens trobem, doncs, amb força estudis de moviments portuaris, acompanyats de llistes de patrons de nau i de productes, amanits d'incertes dades estadístiques. Aixo, segons la meva opinio, no serveix de res. Cal, és cert, recollir el maxim de notícies possibles, a fi de poder construir amb la major informació un treball de síntesi, on els Paisos Catalans a la baixa edat mitjana es considerin globalment, deixant de banda absurdes reivindicacions de preponderància o capitalitat economico-politica, també als meus ulls mancades de sentit de la realitat historica $i$ errades en el plantejment ${ }^{104}$. No crec que fer una historia de les rivalitats porti enlloc.A més, poc en treurem, de la demostració del trasllat de poder de Barcelona a Valencia, per exemple, si oblidem que la confederació tenia el mateix rei i que les elits mercantils eren les mateixes a la ciutat comtal i a la del Grau, si deixem de banda que les principals companyies comercials actuaven amb seus en ambdós llocs i també a Mallorca, emprant els mateixos mecanismes $i$ estratègies, sempre en la direcció de la major consecucio de guanys $i$ beneficis.

\footnotetext{
${ }^{103}$ La tercera, perd, ha rebut crítiques considerables; vegeu el dossier sobre el seu llibre a - "Revista d'Historia Medieval", 2 (1991), pp.159-189, amb els següents articles: E. CRUSELES, La acumulación del capital comercial a través de la documentación notarial (algunas reflexiones acerca de la obra de Jacqueline Guiral); P. PÉREZ GARCIA, Las senvidumbres de una epistemología utópica: la sociedad valenciana en Valencia, puerto mediterráneo en el siglo XV; M. RUZAPA, Los mudejares en el desarrollo mercantil valenciano del Quatrocientos.

${ }^{104}$ Sembla que aquest és un dels objectius d'un recent article de D. IGUAL, Valencia y Sevilla en el sistema económico genovés de finales del siglo XV, "Revista d'Historia Medieval", 3 (1992), pp.79-116. Article, d'altra banda, força discutible pel que fa a les bases documentala emprades per a intentar bastir la idea de la "centralitat de Valéncia en el Meditemani genoves", car fonamentar-se exclusivement en els protestos de lletres de canvi d'un manc temporal de deu anys a fi de justificar tot un sistems econòmic es, als meus ulls, tan erroni com reconstruir el comerç baixmedieval basat en les exportacions de "coses vedades". En ambdós casos la font utilizzada és massa pobra, incapaç de possibilitar generalitats d'aquestes envergadures.
} 
Hem d'anar en compte, alhora, en el tractament donat a la documentacio, sobretot quan s'usa solament una serie arxivistica 0 un tipus documental únic. Més amunt he posat en evidencia les equivocacions a que una anàlisi poc adequada pot donar lloc. No vull dir amb aixo que sigui desancertat utilitzar una font en concret, sino que el parany resideix a voler bastir una construcció teorica i d'interpretació completa a partir d'un enfocament singular i particular. En aquest sentit, la tasca realitzada a Catalunya, pel que fa a l'estudi des del punt de vista jurídic i de recull de documents representatius, endegada per Madurell, García Sanz i Ferrer Mallol, sobretot per a les comandes comercials, les assegurances i canvis maritims i les societats mercantils, ens sembla molt notable ${ }^{105}$ i d'una utilitat innegable; s'hauria de continuar, com ho ha posat en relleu recentment Antoni Riera, amb la consideració dels nolits ${ }^{106}$. Ara bé, aquests treballs, que faciliten l'accés a un important nombre de dades $i$ ens expliquen en detall cada un dels negocis jurf́dics esmentats, no entren en la vel.leïtat de pretendre donar solucio a les incognites de l'evolucio del tràfic internacional als darrers segles medievals, com es fa, encara enguany, des d'algunes seus $^{107}$. Per acabar, sols insisteixo en el fet que l'accés a un correcte coneixement de les relacions economiques a la Mediterrània i a l'Atlantic, als segles XIII-XV, ens vindrà donat per l'indispensable treball conjunt de recopilacio, confrontacio, comparacio i sintesi posterior de dades, labor que hauria d'unir els esforços realitzats en el buidatge d'arxius catalans -no tan sols els de les tres capitals, sino tambe ampliats als centres portuaris de mitjana i petita importància- amb els realitzats als centres estrangers que mantenien un trafic predominant amb les terres catalanes: tan sols aixi arribarem a poder bastir la cartografia dels intercanvis, assenyalant els moments de major o menor intensitat, les àrees d'acció $\mathrm{i}$ el joc de les estrategies economiques.

${ }^{105}$ Obres citades a la nota 9.

${ }^{100}$ A. RIERA-G. FEUU, Activitats econdmiques, a Historia de Barcelona dirigida per J. Sobreques, vol. 3: La ciutat consolidada (segles XIV i XV), Barcelona, Enciclopedia CatalasaAjuntament de Barcelona, 1991, p.193.

${ }^{107}$ Em refereixo als intents d'explicació global a partir d'una sola font documental com les assegurances martimes; vegeu E. CRUSELES, Jerarquización y especialización, op.cit; o l'encara més ambiciós de D. IGUAL, Valencia y Sevilla, cit. 
A) SORTIDES DEL GRAU

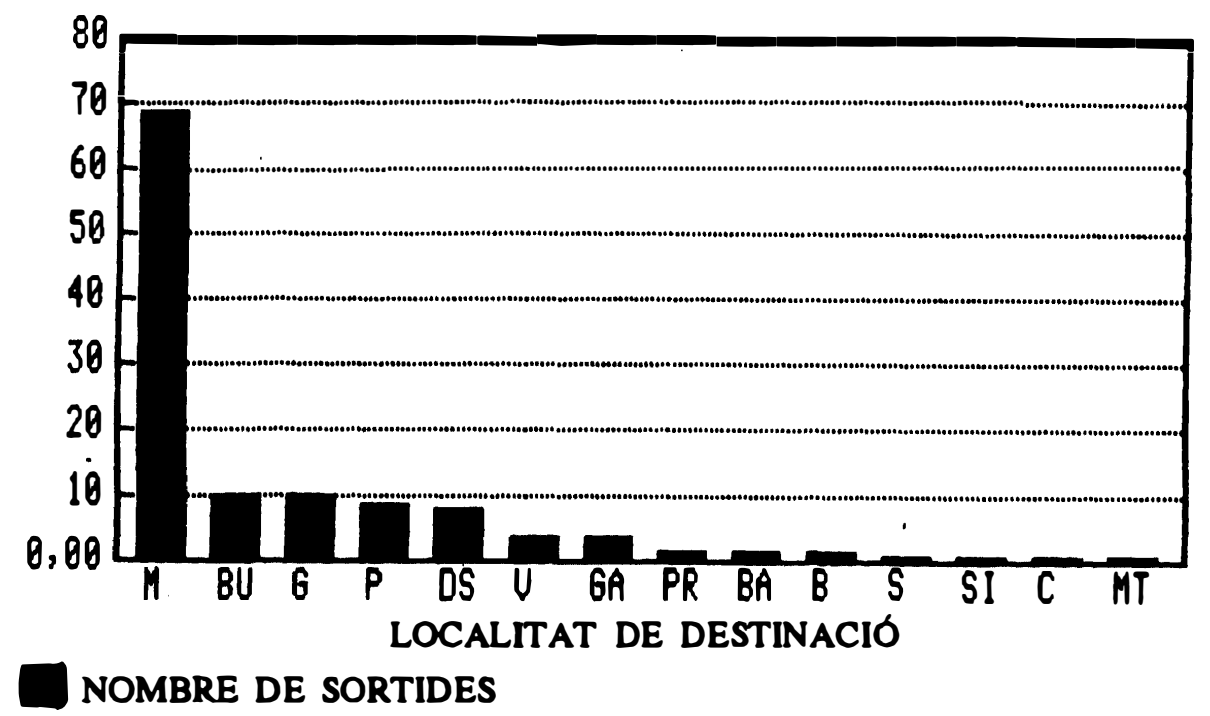

$M=$ Mallonca; $B U=B r u g e s ; \quad G=G e ̀ n o v a ; P=P i s a ; D S=$ destinació desconeguda; $V=$ Venżcia; $\mathbf{G}=$ Gaeta; $P R=$ Provença; $B A=$ Barcelona; $B=$ Barbaria; $S=$ Sardenya; $S I=$ Sevilla; $C=$ Cullora; $M T=$ Messina/Trapani.

B) ARRIBADES AL GRAU

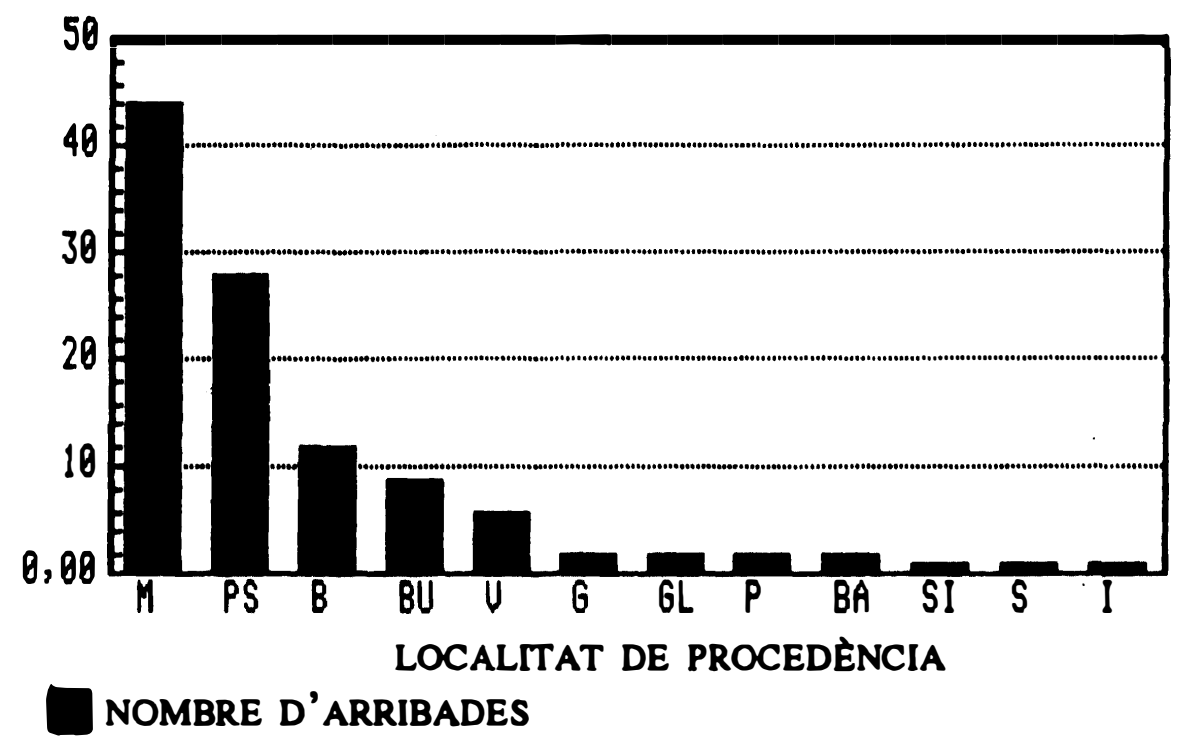

$\mathbf{M}=$ Mallorca; $P S=$ procedzncia desconeguda; $B=$ Barbaris; $B U=$ Bruges; $V=$ Venżcia; $\mathbf{G}=\mathbf{G Z}$ nova; $\mathbf{G L}=$ Galícia; $\mathrm{P}=$ = Pisa; $\mathrm{BA}=$ Barcelona; $\mathrm{SI}=$ Sevilla; $S=$ Siclia; $I=$ Eivissa 


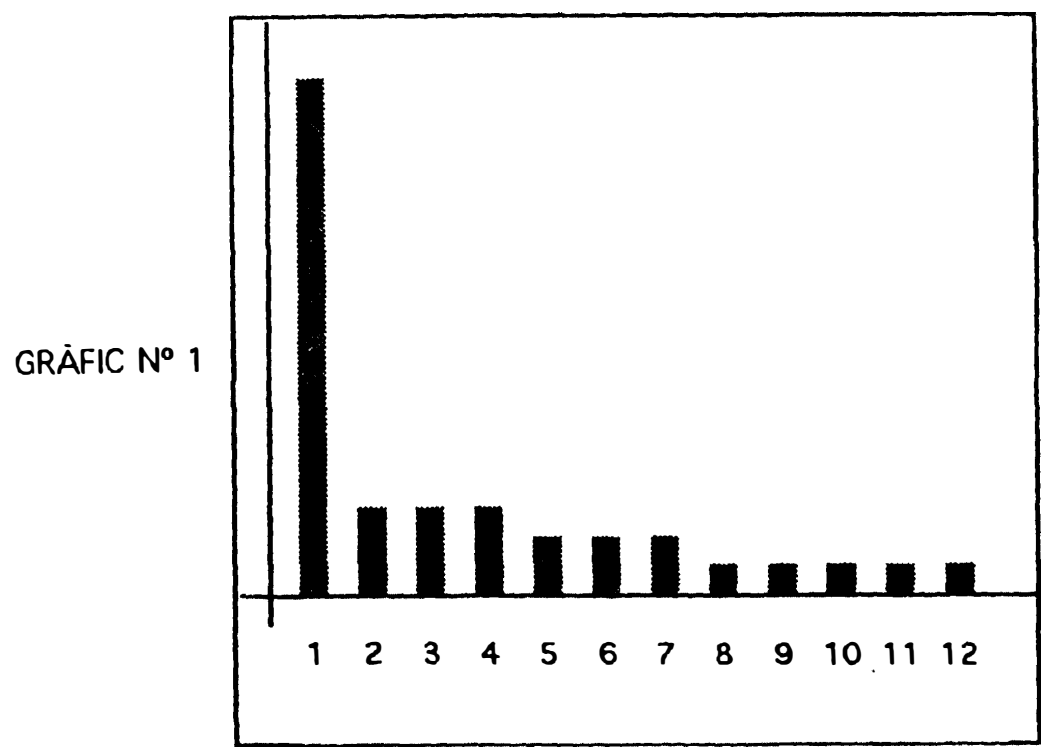

LLEGENDA. 1: Mallorca, 2: Sevilla, 3: Eivissa, 4: Barcelona, 5: Perpinyà, 6: Nord d’Āfrica 7: França, 8: Gènova, 9: Tarragona, 10: Flandes, 11: Caller, 12: Menorca

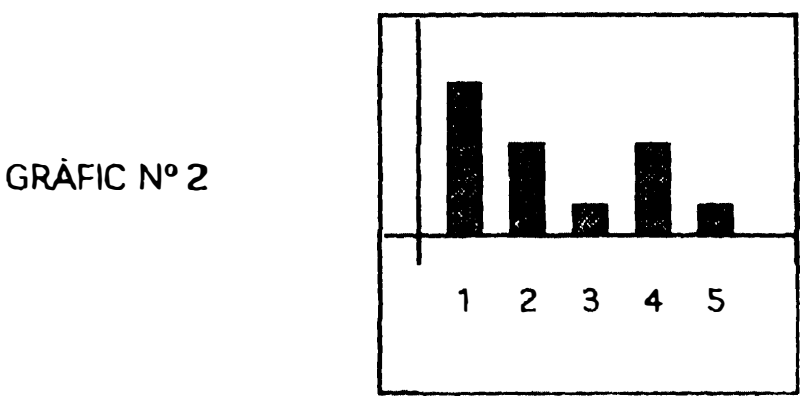

LLEGENDA: 1:Nord d'Ảfrica, 2: Catalunya, 3: Itàlia, 4: València, 5: França. 


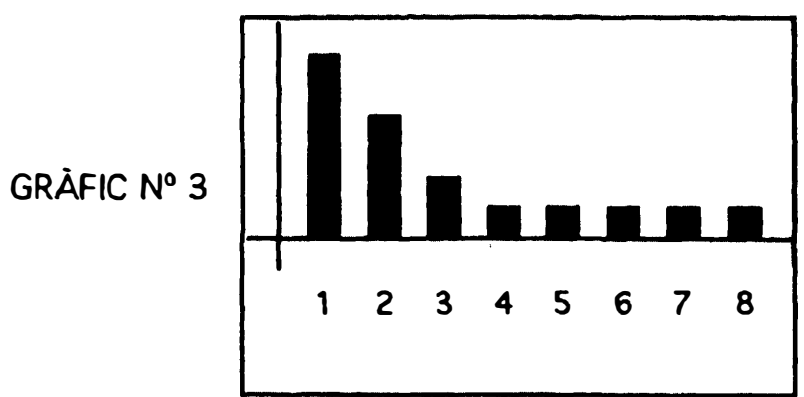

LLEGENDA. 1: Nord d'Äfrica, 2: Ultramar, 3: Illes, 4: França, 5: Mallorca, 6:València, 7: Tarragona, 8: Gènova

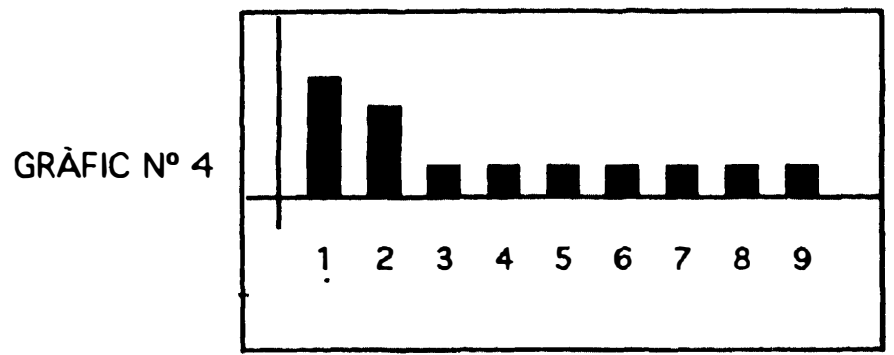

LLEGENDA. 1: Illes, 2: Ultramar, 3: Provença, 4: Balears, 5: Nord d’Ảfrica, 6: València-Alacant: Múrcia, 7: Itàlia, 8: costa catalana, 9: Sevilla

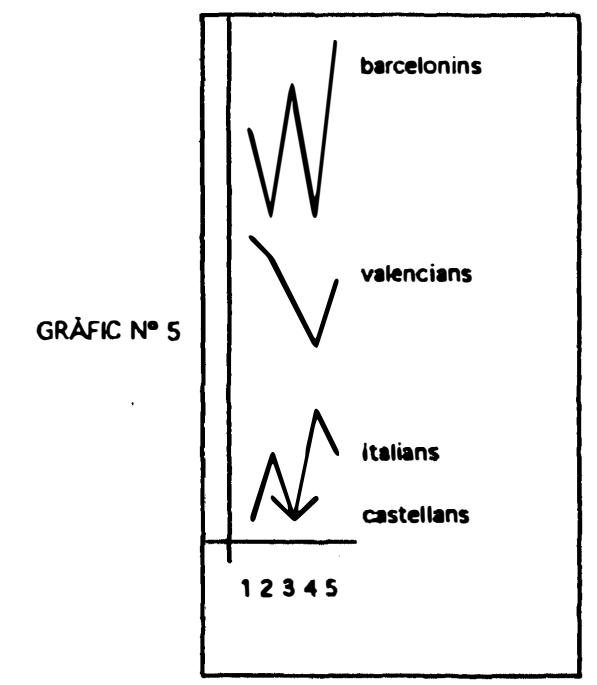

LLEGENOA. 1: 1320, 2: 1325, 3: 1330, 4: 1335, 5: 1340 


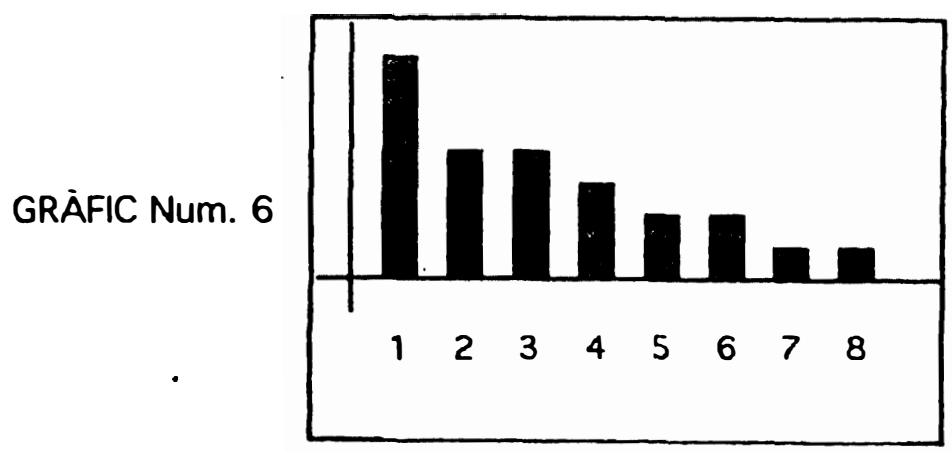

LLEGENDA. 1: Nord d'Africa, 2: Mallorca, 3: Sardenya, 4: Barcelona, 5: Gènova, 6: Sevilla, 7: Pisa, 8: Brest

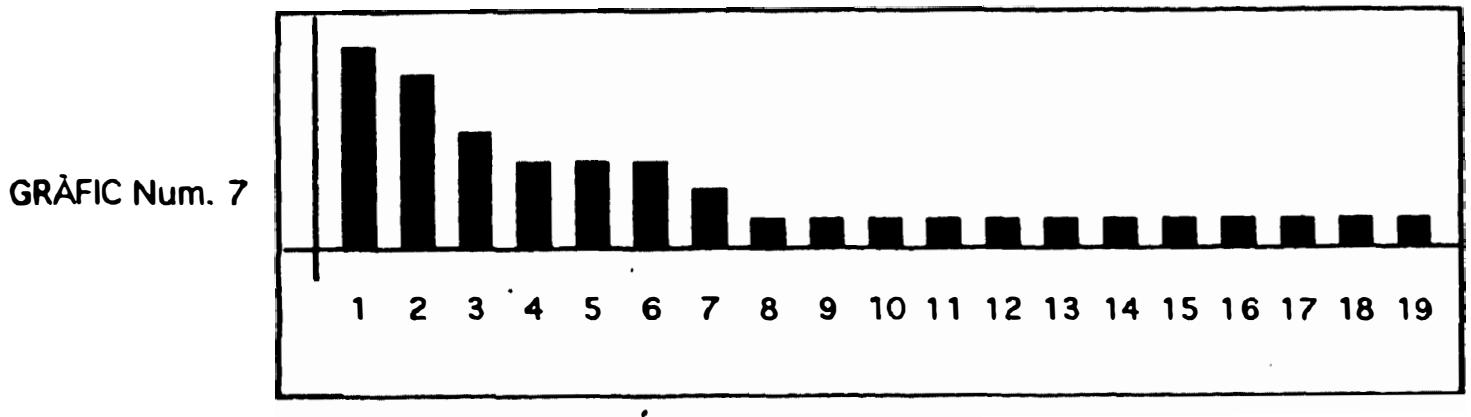

LLEGENDA. 1: València, 2: Colliure, 3: Mallorca, 4: Narbona, 5: Agde, 6: Sant Feliu de Gulxols, 7: Serignan, 8: Caller, 9: Tortosa, 10: Alguer, 11: Xipre, 12: Rossell6, 13: Peniscola, 14: Vilafranca del Penedès, 15: Castell6, 16: Girona, 17: Saragossa, 18: Sardenya, 19: Aigues Mortes.

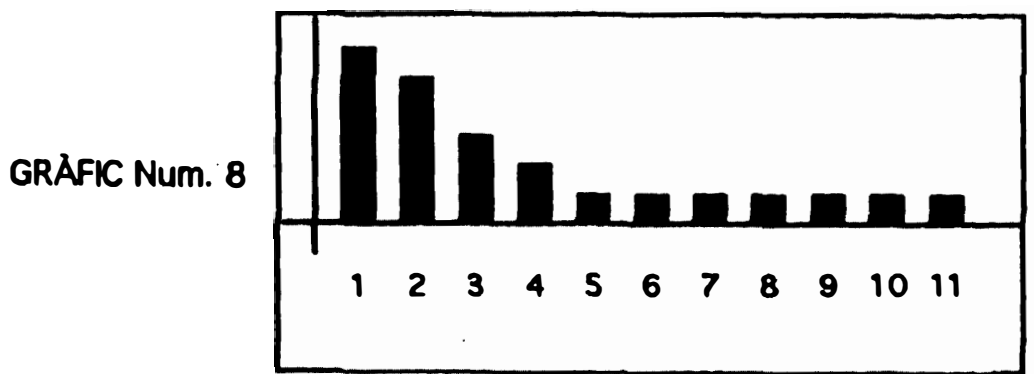

LLEGENDA. 1: Genova, 2: Ultramar, 3: València, 4: Illes, 5: Nord d'Äfrica, 6: Lisboa, 7: Venècia, 8: Provenç, 9: Blanes, 10: Mallonca, 11: Tarragona 


\section{RÉSUMÉ}

Cet article considere des aspects relatifs à la meilleure compréhension de l'économie catalanne du XIV ${ }^{e}$ siècle en un sens concret; de façon plus génerique son rol au marc des inter-relations avec les centres portuaires italiens de la même epoque, tous dans un espace plus large que serait capable de penser un monde méditerranéen d'échanges, même l'atlantique.

C'est un travail conjoint, mais pas redacté à quatre mains, sinon complementaire; c'est à dire, il est conçu à travers de deux points de vue et à travers du travail de recherche de deux historiennes, meme si les objectifs ont été coincidents. De cette façon, nous trouvons à la fin que une situation historique unique peut être considerée, en dependance des fonts d'archive, de manière sincronique et diacronique, en pensant à la fois en l'évolution et en le temps concret. En plus, c'est un intent de confrontation de résultats, d'interpretation et de constatation des événements.

\section{SUMMARY}

This article thinck over the aspects relatives to the better understanding of catalan economy at the XIV century in a concret sense; generaly this role into the interelations'marc with the port italians centers at the time, all in a espace more large able to thinck a mediterranean world of echanges, an atlantique too.

This is a conjoint work, but does not a four hands'redaction, is complementary because its conceived behind two points of view and behind the investigation work of two historians, even though the objectifs are coincidents. In this way, we meet at the last what a only historic situation can be understanding, in dependence of the archive's sources, in a sincronic way or diacronic, thinking at the same time in the evolution and in the singular time. In more, this is an intent of the results' confrontation, interpretations and events' constatation. 